\title{
"Proactive Control" The Case of Community Policing in Ottawa
}

\author{
by
}

\section{Chanel Ghazzawi}

A thesis submitted to the Faculty of Graduate and Postdoctoral Affairs in partial fulfillment of the requirements for the degree of

Master of Arts

in

Sociology

Carleton University

Ottawa, Ontario

(C) 2013

Chanel Ghazzawi 


\begin{abstract}
$\underline{\text { ABSTRACT }}$
This research investigates how the Ottawa Police Service, a police organization that is committed to community policing, operationalizes the paradigm and further considers some of the benefits and challenges of the collaborative approach. The thesis argues that despite the ideals of community policing, there exist significant limitations that challenge police officers' present capacities to engage in partnerships with the community. Such limitations include an ambiguous conceptual understanding of community policing, community mobilization efforts that are based on the assumption that communities can be readied and are willing to participate in crime prevention programs established by the police, a traditional police structure that cannot effectively sustain community policing reforms, and an underlying police subculture that does not subscribe to proactive policing. The findings suggest that although the Ottawa Police Service is committed to community policing, they must consider addressing the identified limitations in order to effectively operationalize community policing and maintain accountability.
\end{abstract}




\section{ACKNOWLEDGMENTS}

To all the police and community participants that took the time to sit with me and contribute their thoughts, perspectives and insights, I am thankful.

To Dr.Aaron Doyle, the Graduate Coordinator for the Department of Sociology and Anthropology. I would like to express my deepest gratitude for always taking the time to sit with me and for recognizing my potential as a graduate student.

To my thesis advisor, Dr.Michael Mopas, Department of Sociology and Anthropology, for his guidance, attentive support and constructive criticisms, all of which have made this thesis experience a rewarding one.

To Dr.Toby Gelfand, the retired Hannah Chair of the History of Medicine at the University of Ottawa and great friend. Thank you for inspiring me to pursue graduate studies and for teaching me to appreciate the value of history in understanding the social world. I will always be grateful for Roast $\mathrm{n}$ Brew chats and trips to Pollux, both of which offered me a place to relax away from academic work.

To all my friends that patiently waited for me to complete my thesis and for understanding that the weekend was devoted to my studies. Special thanks to one of my greatest friends, Victoria Scrubb I am indebted to her for her insightful comments and editing of this thesis.

Last and certainly not the least, to my wonderful family, I am especially grateful for their unwavering support and unconditional love. To my dad, for his invaluable guidance, to my mom for her loving reassurance and to my sister who always offered a comforting smile and sweet baked goods! 


\section{TABLE OF CONTENTS}

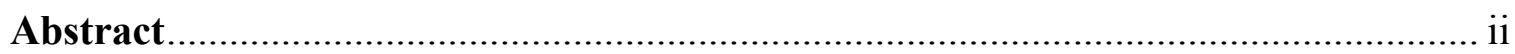

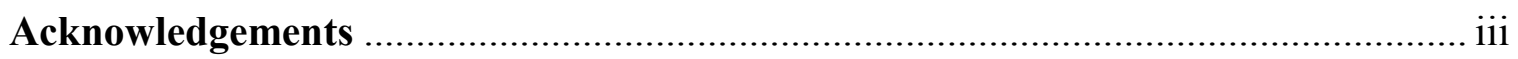

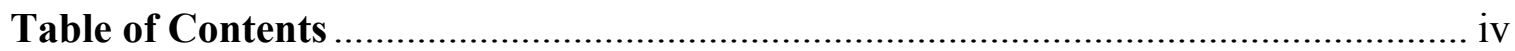

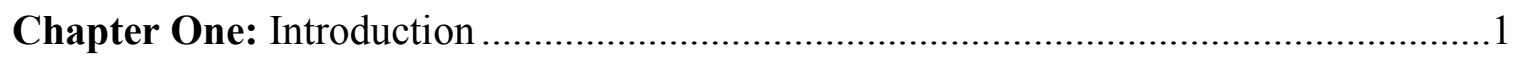

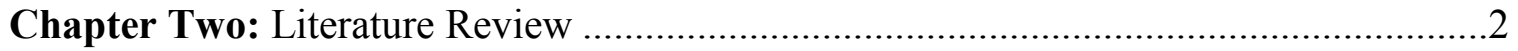

2.1 Shift in Political Rationality: From Welfarism to Neo-Liberalism ...................

The quest for community as the solution to crime control...........................5

2.2 Exploring Community Policing .................................................................6

From reactive to proactive policing ......................................................6

Dimensions of community policing .......................................................... 7

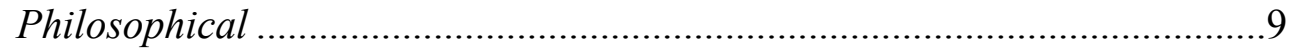

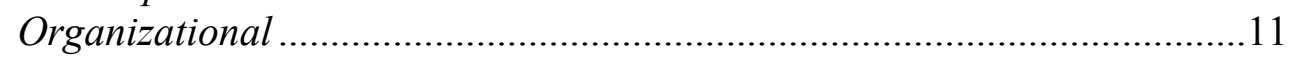

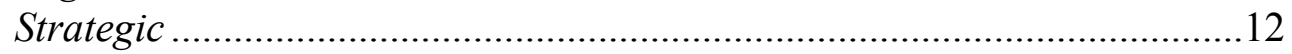

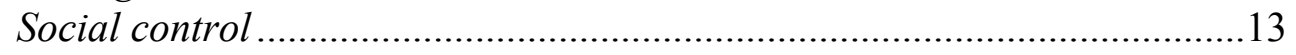

The value of community policing ............................................................14

The challenges of community policing ......................................................16

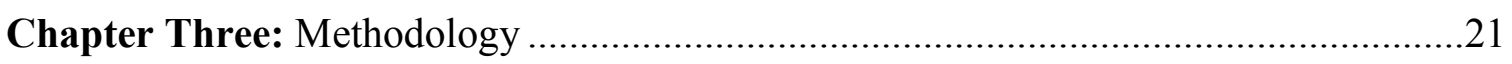

2.3 Theoretical Approach of Research Project ...............................................21

3.1 Research Methodology: The case study ...................................................22

Research focus and the study question ................................................22

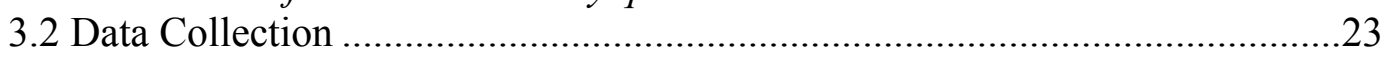

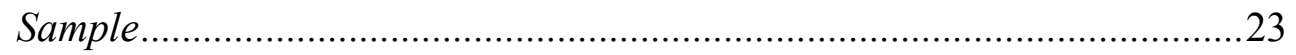

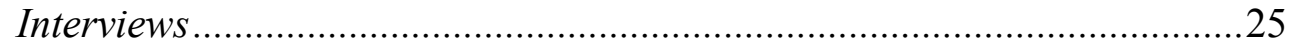

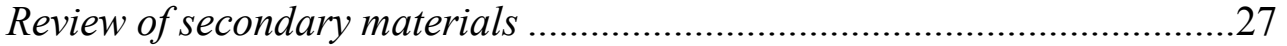

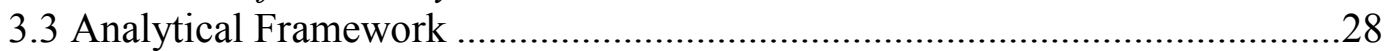

Content analysis...........................................................................28

3.4 Limitations of Case Study Research Methodology ......................................30

Chapter Four: Tension One: The Conceptual Limitations of the "Community" ...........33

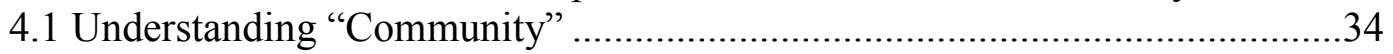

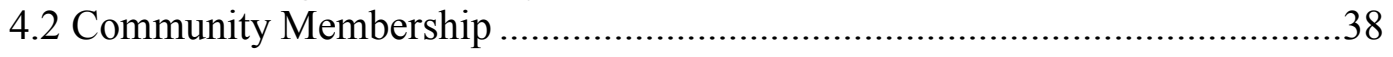

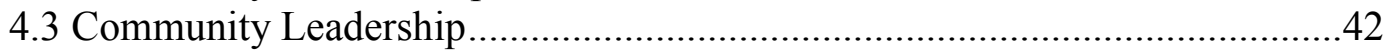

Chapter Five: Tension Two: Mobilizing a Responsibilized Community ......................46

5.1 Understanding Community Mobilization ..................................................47

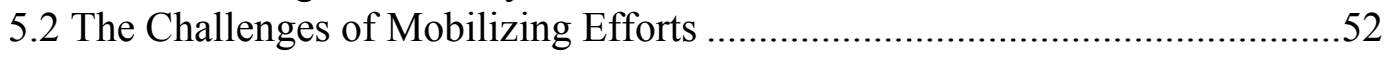

5.3 The Effectiveness of Mobilizing Initiatives...............................................55 
Chapter Six: Tension Three: Conflicting Police Models ..........................................58

6.1 Police Organizational Structure .....................................................................55 Accommodating proactive policing in a traditional police structure ........59 Structural obstacles in community policing reforms .............................62

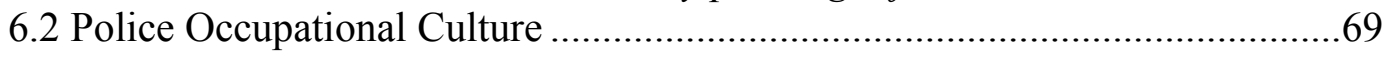

Proactive policing as "real" policing .................................................69

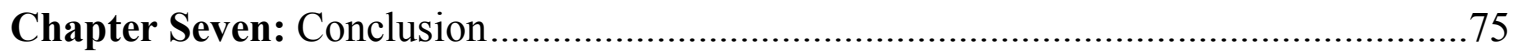

7.1 Recommendations for Future Research ...................................................79

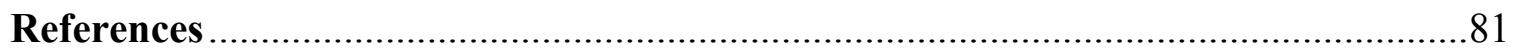




\section{CHAPTER ONE}

\section{Introduction}

Community policing is a paradigm predicated on the assumption that collaborative approaches between the police and the community will facilitate informal social control mechanisms to manage risk and prevent crime. The considerable literature on community policing is replete with general theories that support the assumption that the most effective basis of social order and control is community-based (Eck \& Rosenbaum, 1994). However, police scholars have underscored the limitations of community policing, including policies and practices that challenge police organizations in achieving effective problem solving and establishing community partnerships (Eck \& Rosenbaum, 1994, Skolnick \& Bayley, 1996 and Trojanowicz \& Bucqueroux, 1990).

The following exploratory case study seeks to provide a better understanding of the community-policing concept. Benefiting from the extensive literature on community policing as a foundation, this research considers how the Ottawa Police Service, a police organization that is committed to community policing, operationalizes the paradigm. In the process, the research further seeks to identify the challenges of community policing and to extend the benefits of collaborative approaches between the police and the community.

Through the application of a social constructionist approach that considers the way in which individuals see and describe their social world, this study investigates how the police and community participants understood the way in which community policing is operationalized and how they perceived and gave meaning to their experiences within the police-community nexus. The thesis argues that despite the ideological beliefs of 
community policing, at the level of practice, three underlying tensions exist that challenge the Ottawa Police Service's present capacities to engage in partnerships with the community. These three tensions include an ambiguous conceptual understanding of "community", community mobilization efforts that are based on the assumption that communities can be readied and are willing to participate in crime prevention programs established by the police and a traditional police structure and underlying culture that cannot effectively sustain nor subscribes to proactive policing.

The research project is presented as follows. Chapter Two provides a review of the literature on community policing, and notes the historical conditions and processes that have given rise to community policing practices and policies. The chapter then considers the underlying epistemological assumptions of community policing, including its value and challenges. Chapter Three discusses the theoretical orientation and methodological approach that were used to develop and conduct this research. Chapters Four, Five and Six, present the qualitative interviews with police and community participants. The results of the interviews are categorized by three emergent themes, namely, the concept of community, community mobilization and the police organizational structure and occupational culture. Each of the chapters focuses on presenting a tension that surfaced during the interviews and outlines the host of complex contradictions, inconsistencies and sites of resistance that escort them. Chapter Seven concludes the thesis and offers a final discussion on the key findings of the research. 


\section{CHAPTER TWO}

\section{Literature Review}

This chapter provides a review of the literature on community policing. First it explores the historical conditions and processes that have given rise to our present practices and policies in community policing. Next, the chapter outlines the relevant empirical research on community policing, including the underlying epistemological assumptions on which the paradigm turns and its concomitant implications.

\subsection{Shift in Political Rationality: From Welfarism to Neo-Liberalism}

Throughout the first half of the twentieth century, significant changes in capitalist systems around the world encouraged many western societies to abandon liberal principles and adopt welfarist approaches to governance. The welfarist mode of government translated into a system whereby state centered approaches to public and social policies gradually became embedded within an ensemble of institutions and a series of aspects that were once characterized as private, were now entrenched in varying degrees of state interventions (Garland, 2001). While the diversity of the programs that emerged had been inspired by different aims and principles, their underlying basis were to impel the state to calculate, calibrate and govern both moral and economic affairs (Rose \& Miller, 1992). However, by the 1970's and onward, the welfare state began to unravel as economic conditions were changing and the demand for social services by citizens outweighed the state's capacity to sustain them. In order to pay for social services and other programs, the state faced the choice of increasing taxes, running deficits or both and consequently, contributed to government overload, fiscal crisis, dependency and rigidity (Kelly \& Caputo, 2011, p.27). 
The turbulent economic climate of the 1970's instigated the need for changes to the political landscape, and a new political ideology in order to re-code the locus of the state. Accordingly, during the 1980 's neo-liberal political rationalities gained currency and were weaved into political discourse and initiatives. Political commentators have recognized a series of trends in the development of neo-liberalism, the most profound of which has been described as the re-organization of state responsibilities (Kelly \& Caputo, 2011, p.28). Neo-liberalism was based on the ideological thrust that the state would minimize its role in society by divesting itself of costly services and programs. Yet, at the same time, it believed that individuals, rather than the state, should be responsible for their own welfare and personal well-being. The corollary of this proposition was that by divesting services and ascribing greater freedom to citizens, they would become "responsibilized" individuals that would look out for their own good and the collective good of society (Garland, 2001, p.124).

Hence, "governing through community" emerged as a crucial element in contemporary discourse for government (Rose, 1999). Increasingly, various functions that were once the responsibility of the state were re-organized and "downloaded" to the community setting. The shift towards the community setting was rationalized by the state as an approach that would support direct democracy, as social programs would be delivered by local groups and, in turn, would contribute to a more efficient service delivery (Kelly \& Caputo, 2011). The emphasis on the community was also profoundly rooted in the recognition that good governance was animated by collective life, the bonds of culture, the ties of locality, common virtues and a commitment to the common good among individuals sharing a common geographical space (Rose, 1999 and Etzioni, 1997). 


\section{The quest for community as the solution to crime control}

Amidst the dynamic transformations of the 1960's, the "downloading" of responsibility to the community became integrated into the field of crime control. Increasingly, government agencies began recognizing that crime control was "beyond the state" and that they were limited in their capacities to maintain "law and order" (Garland, 2001). In response to this concern, the state sought to re-orient criminal justice institutions by establishing adaptive responses that would relocate and redefine the responsibilities for crime control. These adaptive responses led to the development of a new infrastructure of crime control that was strongly oriented towards the objectives of prevention, security, harm-reduction, loss-reduction and fear-reduction (Garland, 2001, p.17). This crime prevention infrastructure did not replace the traditional crime control priorities of prosecution and punishment, but rather policies and programs became increasingly oriented to include a commitment to the local level.

The redistribution of crime control tasks was rendered by employing both direct mechanisms of control by means of the police and the criminal justice system in combination with indirect mechanisms that would support the development of a “preventative partnership" between state agencies and non-state actors (Garland, 2001, p.17). Otherwise considered as the "responsibilization strategy", the raison d'etre of this approach was to decentralize crime control so that government agencies could "build" communities whose vectors and forces could be mobilized and whose citizens would be willing and able to act rationally in their own self-interest and that of society's to reduce and prevent crime (Beck, 1992). 
Governing through community then, was understood as a novel way to organize programs and techniques that would be self-managed through collective allegiances. The efforts to relocate the work of crime control at the local level led to the development of reform initiatives such as community policing and community crime prevention. Community policing and community crime prevention strategies were considered to be innovative and ideological responses to crime control as their efforts sought to enlist the help and support of community residents and agencies in responding to crime concerns and offered the political promise of responsive and responsible policing (Garland, 2001, p.23). The "out-reach" approach of community policing and community crime prevention methods provided a solution to the ongoing search for "community" in modern urban society, as non-state actors and informal crime-control practices were linked to the more formal activities of police organizations.

\subsection{Exploring Community Policing}

\section{From reactive to proactive policing}

By the 1980 's, community policing quickly emerged as a dominant ideology and organizational model of progressive policing in Canada (Eck \& Rosenbaum, 1994). The development of community policing was accompanied by an all-pervasive rhetoric and marked significant shifts in the traditional police ideologies and practices (Garland, 2001). The traditional model of policing is characterized by a paramilitary structure that is highly bureaucratic and centralized. Furthermore, the traditional policing model considers the police function to involve crime control, emergency responses, serving justice and the delivery of non-emergency services (i.e. traffic control). Murphy (1988) 
contends that the social organization of the police is re-actionist and enforcement oriented and translates to a service delivery model that is characterized by:

i) Incident orientation: The primary focus of the police is to respond to incidents, calls for service and emergency.

ii) Reactive orientation: Police operations are centered on responding to events as they occur and little time is spent in proactive engagements.

iii) Limited analysis: A broader analysis of the problems that precipitated the events is limited as officer availability is provided based on operational priorities.

iv) Limited response: The responses to crime are limited to the standard law enforcement strategies.

v) Means over ends: An emphasis is placed on response efficiency versus the effectiveness of developing strategies that will prevent, reduce or eliminate problems (p.180).

The adoption of community policing marked a departure from the traditional policing model as it was considered to be an alternative model that would address some of the limitations of the traditional one, namely, the expensive and expansive police services, declining neighbourhood safety in core urban areas, and social-based conflicts (i.e. race, class etc) (Murphy, 1993). By foregoing their monopoly of crime control tasks and exhorting collaborative approaches, community policing was believed to offer the solution to the ongoing search for community in modern society, the political promise of responsive and responsible police services, and operational strategies that would enhance police effectiveness (Murphy, 1988).

\section{Dimensions of community policing}

Despite the widespread adoption of community policing in Canada, the literature on community policing suggests that the concept has no single theoretical or practical definition (Manning, 1984 and Kelling, 1995). Therefore, organizing the diverse 
connotations of community policing into a coherent whole may pose to be a challenge, as the perceived nature and scope of the term is broad and fluid. As Greene and Mastrofski (1985) appropriately highlight:

"It should be emphasized that community policing means many things to many people. It is at once an ideology, an organizing framework for many police activities, and a set of individual programs. Community policing can be seen as a convergence of several police reform efforts of the past" (p.xiii).

However, Friedmann (1992) claimed that understanding the concept of community policing requires to first consider the varying perspectives of those involved in its practice, that is, the police and the community. According to Friedmann, from the perspective of the police, community policing is a means of engaging with community resources to achieve the end of enhanced crime control and prevention. The goal for police is to increase their interaction with the public in hopes of accumulating greater intelligence that would assist in the prevention and solving of crime. On the other hand, from the perspective of the community, Friedmann claims that community policing is an opportunity to improve police services, provide greater accountability and support for their involvement in decision making to matters pertaining to public safety and order maintenance. Friedmann also offered a joint police-community perspective that is based on the underlying notion that crime is the result of fundamental societal problems that cannot solely be addressed by the police and that reactive policing approaches cannot effectively deal with all public safety issues. Therefore, the joint police-community perspective emphasizes the importance of the proactive engagement of officers with the community to contribute to a method of policing that maintains quality of life 
considerations, human rights, and civil liberties, all of which are characteristic of liberal democracy. In light of these perspectives, Friedmann comments:

"Community policing is a policy and a strategy aimed at achieving more effective and efficient crime control, reduced fear of crime, improved quality of life, improved police services and police legitimacy, through a proactive reliance on community resources that seeks to change crimecausing conditions. It assumes a need for greater accountability of police, greater public share in decision-making and greater concern for civil rights and liberties (p.4)"

Although community policing can take a number of directions, a review of the

literature does support that community policing as it is currently constructed is

underpinned by a set of policing principles and practices, which can be understood using four dimensions: philosophical, organizational, strategic and social control.

\section{$\underline{\text { Philosophical }}$}

The philosophy of community policing advocates the principle that the solution to community crime and disorder requires a collaborative approach between the police and the community. As described by Trojanovwicz and Bucquerous (1990), a community policing philosophy is one that permeates throughout the entire police department and is part of its daily operations:

"Community policing is not a technique....The entire department must be infused with the community policing philosophy with Community Police Officers as the department's direct link to average citizens. Community policing is not something to be used periodically, but it is a permanent commitment to a new kind of policing that provides decentralization and personalized community problem solving (p.20)".

Building on this philosophical understanding of community policing as a new source of organizational ideology, some scholars have listed key "ingredients" or elements that they believed are expressed in community policing. Skogan and Harnet 
(1997) identified four key elements that they considered were prevalent to a community policing philosophy, citing them as: a commitment to a broader problem oriented policing philosophy, a decentralized organizational management, police response to citizen identified issues and problems and police helping community by serving as catalysts. However, the most comprehensive definition was developed by Normandeau and Leighton (1990), who provided additional elements to explain community policing. Along with the four principles identified by Skogan and Harnet, Normandeau and Leighton noted that a community policing philosophy is one that involves a shift of mission of police officers to peace officers, the practice of community consultation, proactive approaches to policing, the development of crime prevention activities, interagency co-operation, interactive policing, reducing the fear of victimization, the development of police officers as career generalists, the development of flatter organizational structure and accountability to the community.

Taken together, the principles demonstrate that as a philosophy, community policing is a new source of organizational ideology and a "new way of thinking" about the police function and its role with citizens (Rosembaum, 1994). Furthermore, the various philosophical elements of community policing indicate that collaborative approaches between the police and the community differ significantly from the traditional policing model, the former emphasizing an element of proactive approach and the later a reactive modus.

To demonstrate the difference between the traditional and community policing models, Trojanovwicz, Kappeler and Gaines (2002) identified a number of communitybased elements that differentiate the two. The scholars maintained that a community 
policing philosophy differs from the traditional policing approach as it includes a broader police function that incorporates fear reduction, order maintenance and community health along with its functions of crime fighting and enforcement. Whereas the traditional police model emphasizes a centralized, detached, reactive approach that implies a more professional interaction between the police and citizens, the community policing philosophy dictates the opposite and encourages decentralization, transparency and proactive approaches involving the police and the community. Such proactive engagements are accomplished by sharing power (i.e. recognizing that citizens have the legitimate right to control their agenda and make demands upon the police), using creative approaches to address community concerns and problems and by recognizing that variation exists among neighbourhoods and that police officers should follow the "will of the community" when dealing with community issues and enforcing the law (p.7$10)$.

\section{Organizational}

Secondly, the philosophical shift in the police department's understanding of their mission requires changes in their structure. For this reason, police scholars have also argued that community policing possess' an organizational dimension. Scholars rationalize that when a police department subscribes to the community policing philosophy, their mission statement includes references to their value system and personnel's orientation, thus setting the stage for the development and implementation of community policing strategies and tactics (Trojanovwicz, Kappeler and Gaines, 2002, p.12). 
Traditionally, the police organizational structure is characterized as hierarchical, paramilitary, highly bureaucratic and surrenders to a top-down approach of decisionmaking. Contrarily, the community policing model emphasizes paradigmatic shifts in the police organizational apparatus that are "flatter" (less hierarchical), decentralized and recognize the value of front-line officers experiences (Skolnic and Bayley, 1986, p.92). A classic decentralized approach of community policing is the establishment of Community Police Centres. The Centres, which are operated by Community Police Officers, are a central hub for crime prevention initiatives and provide officers with greater autonomy to engage with the community in collaborative efforts. Another common organizational change that is implemented to accommodate community policing involves changes in performance measures. Whereas traditional policing measures performance based on crime statistics, the number of arrests and traffic stops, community policing encourages performance measures that are relevant to the community, such as surveys to measures citizen satisfaction with police (Willis, 2001).

\section{$\underline{\text { Strategic }}$}

Thirdly, because community policing introduces a change in the relationship between the police and the community, some police scholars claim that community policing entails the adoption of key strategies. These strategies link the broad philosophical principles of community policing to specific practices that can be implemented by police services. In discussing the strategic dimension of community policing, Trojanovwicz, Kappeler and Gaines (2002) expressed that community policing strategies maintain an element of geographical permanence, as officers are assigned to work in communities on a permanent basis (in Community Police Centres, for example). 
It was believed that this geographical permanence would provide the officer with the opportunity to identify with an area and focus their attention on solving specific community problems, while fostering a level of geographical accountability. As a strategy, the scholars also associated community policing with tactical approaches such as foot patrol, team policing, and crime prevention programs.

Gordner (1996) expanded on Trojanovwicz, Kappeler and Gaines, adding that the strategic component of community policing encourages positive interactions with the public and fosters active partnerships that allow both the police and the community to work together in identifying community issues. According to Gordner, community policing introduces a change in the relationship between the police and the community, one that is based on mutual trust, respect and accountability. Therefore, community engagement strategies become essential components in motivating the community's involvement in a crime control program such as Neighbourhood Watch and encouraging them to report suspicious or criminal activity.

Gordner also placed emphasis on a problem-solving orientation of community policing. Whereas traditional policing approaches are based on calls for service, quick responses and short-term solutions, problem-solving involves comprehensive response methods that seek to understand the issues at hand and provide meaningful long-term solutions. Situational crime prevention is a form of problem-solving as it provides opportunity-reducing measures that are directed to specific crimes, involve changes in the immediate environment and reduce the rewards of crime as perceived by the offender. 


\section{$\underline{\text { Social control }}$}

Klockars (1989) offered a fourth critical dimension of community policing, noting that it is a movement whose purpose is to "conceal, mystify and legitimate" police distribution of coercive force (p.249). According to Klockars, community policing is a covert attempt of police to penetrate communities in order to gain intelligence and acquire information. Garland (2001) also extends the community policing dimension of social control noting that it is a mechanism used for government to "govern from a distance", and to transform its mode of exerting control (p.171). Garland claims that the role of the Community Police Officer is an example of a "new specialist" that has emerged over the last twenty years to target criminogenic situations through situational crime prevention programs. Such situational crime prevention programs move away from the individual offender and focus on establishing situational controls, channel conduct away from temptation and direct the social control capacities of citizens and communities. Crime control therefore becomes the responsibility of a number of social actors as citizens are encouraged to be engaged in the facilitation of targeted action with police by identifying areas in which collective risks are perceived as high and by facilitating crime control practices (Crawford, 1995).

\section{The value of community policing}

Based on the various dimensions described of the community policing concept, it is clear that the model is complex and involves a significant shift in the way the police understand their role and engage with the community. Although there are several defining characteristics of community policing, police scholars have identified value in its application that are aimed at both the community and the police. For the community 
participating in community policing initiatives, supporting scholars claim that it significantly impacts citizens' attitudes with police. Based on surveys that had been conducted prior to and post implementation of community policing strategies (i.e. establishment of crime prevention programs, community organizing events involving the police etc) community residents' satisfaction with their neighbourhoods, their evaluation of the police and their overall fear of crime and sense of safety within their communities were more positive (Palmiotto, 2001, p.222). Similarly, Skolnick and Bayley (1988) commented that the public's engagement in community policing provides them with a greater view into police activity, increased involvement in police initiatives and police accountability. However, it is important to emphasize that while the underlying assumption of the community is that community policing will increase safety and security in their neighbourhoods, police scholars suggest that community policing has not yet been sufficiently evaluated to conclude that the approach produces safer and more secure communities.

Skolnick and Bayley also cited benefits of community policing for police organizations and officers as the approach encourages key values such as consensus building (between the community and the police), grassroots support (an opportunity to increase support for the police with special interest groups), overall heightened police morale (as they interact with supportive members of the public), satisfaction (as officers that are engaged in the initiatives take more independent responsibility to manage them), and professional stature and career development (as it broadens the range of skills required and in turn provides more opportunity for personnel to be valuable) (p.71-73). Furthermore, by investing their time and energy in the neighbourhoods they are working 
in, police officers engaged in community police are more likely to be concerned with the welfare of the community members, thus contributing to a better rapport with residents and an increase in conscientiousness by the police officers in their performance of duties (Wycoff, 1988).

\section{The challenges of community policing}

Despite the strong identification of police departments with community policing, police scholars have noted that it is not short of challenges. Within the community policing literature, the challenges of the paradigm have been identified in terms of its conceptual framework and application both internally for the police and externally for the community.

While conceptually there are many interpretations and principles that are central features of community policing, a critical point of contention has been linked to the ambiguous nature of the concept and its application. Firstly, some scholars have argued that the challenge of defining the concept of community policing is rooted in the ambiguous understanding of the respective terms that embody it: "community" and "policing". For the concept of "community", the uncertainty in its connotation is prevalent as the term attaches itself to a variety of notions. The term can be used to refer to a geographical space (i.e. through physical features of boundaries), a social space (i.e. to describe a collective of people that share common interests) or to imply a sense of identity or commonality among people (Crawford, 1995 and Newby, 1980). The complexity of the term community arises as each of its defining features may highlight components to the detriment of others. More concretely, in the context of community policing, defining the "community" only in terms of a geographical space ignores the 
softer elements that appeal to the commonality of interests among the individuals within the community. Furthermore, considering the "community" only in terms of their shared interests ignores the potential that there may be intra-community conflicts and therefore risks marginalizing the voice of some members (Crawford, 1995).

Similarly, defining the concept of "policing" is also complex, as the state no longer maintains monopoly over the means of law enforcement. This is because transformations in the character of policing have led to the establishment of "networked" policing, which constitutes a blend of policing services that are provided by both the public police and a number of other private agencies (Cooley, 2005). The increase in the number of agents delivering policing services in combination with the changing role of the police officer (i.e. law enforcement is no longer principally what the police do, nor solely what the public demands of them) fails to capture the multifaceted meaning of “policing”.

Secondly, some scholars emphasize the vague programmatic content of the community policing concept, may actually result in the variation of applications and approaches used by police departments (Manning, 1988 and Bayley, 1993). Therefore, police scholars question whether a broad and fluid concept such as community policing can effectively be operationalized and have a substantial impact on the police and the community (Manning, 1988).

Internally, the challenge of community policing manifests itself in the organizational and administrative structure of the police department. Evaluations of community policing programs across Canada denote that implementing and managing reform initiatives such as those suggested by community policing, require a level of 
management skill and sophistication that are beyond the operational capacities of most police departments. Skolnick and Bayley (1988) reiterate that the centralized, hierarchical, quasi-military command structure of traditional police departments remains highly intact and does not support the decentralized authority nature and flexibility of lower ranking officers to take initiative and engage in bottom-up communication, which are essential to community policing. Moreover, the reward structure of traditional police organizations, which is based on quantitative criteria, including number of arrests and traffic stops, does not provide an accurate form of evaluating police officers engaging in community policing approaches that are focused on problem-solving and proactive responses.

Murphy (1993) further notes that although many police departments in Canada have operationally implemented increased foot patrol and Community Police Centre operations and expanded on various crime prevention programs, many of their efforts, while well received by the public as community policing strategies, remain isolated approaches that are unrelated to the general philosophy and practices of the department as a whole. As a result, a police department whose operational philosophy remains highly engaged in crime control and reactive responses, leaves community policing to be an adjunct and unrelated strategy (p.20). In turn, the focus on reactive policing further impacts the training of police personnel. As asserted by Murphy, with a strong focus on reactive methods, there are little training opportunities for proactive approaches that would foster the development of essential strategies such as effective communication with community members and logical deductive reasoning. 
Along with some of the structural and administrative challenges that exist for community policing, police scholars have also noted a cultural dimension that impacts the implementation of the approach. As the practice of community policing attempts to change the role and relationship of the police with the community, it requires a shift in climate of police departments and police officers. According to Friedmann (1992), a police subculture exists within police departments that offer police officers a distinct set of values and beliefs regarding their role, duties and obligations in society and to the community. In traditional police subculture, police officers develop a defensive and suspicious attitude towards the public, leading to the solidarity of officers against the community and to their inclination to develop closer relations with one another. Skolnick and Bayley further comment that the police subculture is based on a cynical and skeptical view of society, in combination with an underlying macho attitude (stemming from the crime-fighting image sold to them in Police College) that is often exhibited by junior police officers. This poses as a challenge for officers to accept community policing as an innovative strategy and legitimate mean of crime control (p.230).

External obstacles in the implementation of community policing also exist. One of the most significant challenges of implementing community policing is rooted in its core ideal, that is, building meaningful partnerships with the community to improve public safety. A central requirement of establishing partnerships is the willing participation of the community, a challenge that has confronted many police officers. Skogan (1996) argues that the reasons for the difficulty in acquiring community cooperation stem from a variety of factors, including a lack of time to participate in police-community programs, a lack of understanding on the communities' part of how the concept of community 
policing varies from traditional policing approaches and a general lack of interest in the available programs. Resistance to participating in collaborative approaches with the police was also described by Skogan as being linked to residents' fear or hostility towards police (due to a long standing history of confrontation and alienation) and to a fear of retaliation by gangs, thugs and drug dealers, in neighbourhoods that have high-crime rates (p.31).

Murphy (1993) raises empirical evaluations as an important challenge to community policing. According to Murphy, community policing is difficult to evaluate empirically due to its loosely linked objectives and various programmatic strategies. So while police departments publicize community policing objectives and projects, they fail to accurately indicate whether a program was a success or failure. Friedmann (1992) suggests that the difficulties in the empirical testing of the impact of community policing on police organizations and neighbourhoods is also a product of the ambiguous understanding of the terms "community policing" and "community". The ultimate concern is whether or not the vaguely defined concept posses any substance beyond their emotional, symbolic and communicative values (p.184).

\section{Conclusion}

This chapter sought to highlight the transformative processes that have led to the valorization of the community as an appropriate vehicle for crime control. The chapter also suggested that community policing, while the dominant policing approach for many police organizations, remains complex in its definition as it reflects the various contexts in which it operates (i.e. philosophical, organizational, strategic and social control). While value exists in the approach, including benefits to the community and the police, 
the literature underscores significant challenges, both internally and externally, that continue to impede police departments and the community's practice of community policing. 


\section{CHAPTER THREE}

\section{Methodology}

As outlined in Chapter Two, community policing has become part of the lexicon of police departments in Canada, yet fundamental concerns exist surrounding the translation of community policing from theory to practice (Manning, 1988). In the previous chapter, the concept of community policing was explored, including its key principles and underlying assumptions. In the following chapter, the theoretical orientation and an outline of the methodological approach that was utilized throughout this project will be described in more detail.

\subsection{Theoretical Approach of Research Project}

According to Berger and Luckmann (1967), reality is socially constructed and the sociology of knowledge is therefore concerned with analyzing the processes by which these social constructions of reality emerge. Social constructivism emphasizes several key premises including acknowledging that there exist many versions of reality, that at times may conflict with one another, that the multiple claims and differing view of reality should be analyzed and assessed, and that the role of the research is to facilitate the reconstruction of the knowledge by incorporating their own voice and that of all other participants (Guba and Lincoln, 1994, 105).

As demonstrated in Chapter Two, the community policing literature is replete with definitions of what the paradigm of community policing means, its value to the police and the community and its challenges. The various dimensions described throughout Chapter Two portray the considerable plurality and heterogeneity of the concept of community policing. While it remains a popular concept for police services in 
Canada, there remains no clear consensus in the literature of its meaning and what it is expected to achieve. Furthermore, the construction of the concept itself is highly dependent on who is defining it. Consequently, this research project employs a social constructionist analysis to analyze how the concept of community policing is operationalized and how the social actors engaged in the police-community nexus, namely the police and the community, perceive and give meaning to their experiences.

\subsection{Research Methodology: The Case Study}

\section{Research focus and the study questions}

As described in the previous chapter, the considerable literature on community policing is replete with general theories that support the assumption that the most effective basis of social order is community-based. However, policing scholars have noted the limitations of community policing, including its ambiguous conceptual understanding and a challenge in the police organizations' capacities to sustain the model. Yet, community-oriented policing philosophies have been widely accepted by many police forces across Ontario. Yin (1989) notes that the case study approach is one that benefits significantly from prior research and frameworks that can be used to guide the collection of data and analysis. Therefore, using the extensive literature on community policing as a foundation, this research considers how the police department under study operationalizes community policing and further seeks to explore the challenges and possible benefits of the approach. In order to investigate this, a single case study of the Ottawa Police Service, a police organization that claims a commitment to the philosophy of community policing, was used. 
For the Ottawa Police Service, the main locations of community-policing initiatives are at various Community Police Centres across the City of Ottawa. Led by Community Police Officers, the Centres are the focal points for problem-oriented policing and the primary delivery location of the five core community crime prevention programs offered by the police department (i.e. "Neighbourhood Watch", "Child Print", "Operation Identification", "Home Security Inspections" and "Business Crime Prevention"). In order to evaluate how community policing is translated into practice and specifically the perceived impact on the police and the community, the Neighbourhood Watch program was used to access community and police participants engaged in collaborative approaches. The Neighbourhood Watch program was selected because it is a program that is premised on the joint collaboration between the police and the community and the program is also a core crime prevention program delivered by the Community Police Centres in Ottawa.

This case study was exploratory in nature, as the goal of the research was both to investigate how a social phenomenon is translated in to practice and what its perceived outcomes are on those involved in the social world under study (Yin, 1989). Accordingly, the objective of this case study was to examine the following question: How does the Ottawa Police Service operationalize community-policing? Within the scope of this study, the research also asked the question: What are the perceived challenges and the benefits of community policing for both the police and the community?

\section{$\underline{\text { Sample }}$}

\subsection{Data Collection}

The Ottawa Police Service was selected as the police organization of choice for two reasons: i) the benefit of studying a police organization that has long-term experience 
implementing community policing strategies, especially the crime prevention program Neighbourhood Watch, and ii) the advantage of studying a police organization in my city and not having to travel to meet the study's participants. A non-probability purposive sampling technique was employed to select research participants that represented various positions within the police-community nexus. Participants were selected based on their experience with the Neighbourhood Watch program or within the police organization. A total of seven (7) research participants were selected to participate in this research and they included representatives from both the police and the community.

Police: Three police members were selected to participate including the Community Police Officers that operate within the Community Police Centre of the selected neighbourhood and a senior police member, who was the Sergeant of the Community Police Officers participating in this study. At the time that this research was conducted, one of the Community Police Officers that was interviewed had two years of experience in the position and ten years of experience in the police department, while the second Community Police Officer that was selected had four years of tenure duration as a Community Police Officer and twenty years of experience with the police organization. The Sergeant that was selected for this research offered a managerial perspective of community policing. The senior officer, with thirty years of experience in the police service and five years of experience in community policing, was selected due to his position as the manager for the Community Police Centre under study, and his familiarity with the community as well as with the police organization.

Community: The community that was selected as the focus of this research had long-term experience with the Neighbourhood Watch program, as the Neighbourhood 
Watches in their neighbourhood had been operating since the 1980s. The participants that were selected possessed specialist knowledge due to their work history or role performed within their community and were willing to participate in the research. The four community members that were selected are Neighbourhood Watch Coordinators within the community and were referred to by the Community Police Officers. All four Coordinators had long-term experience with the program and were also affiliated with other associations within their communities. These community members were selected due to their familiarity with the neighbourhood, their active roles in the Neighbourhood Watch program and their willingness to participate in the study.

\section{Interviews}

The advantage of the case study, as noted by Crabtree and Miller (1999) is found in the collaboration between the researcher and the participant. It is believed that through the interactive dialogue participants are able to reveal their views of reality while providing the researcher with the space to understand the participants' actions. This research is concerned with the experiences, perceptions and insights of both police and community members involved in the police-community nexus under study. Therefore, the research has been designed to probe into participants' particular social contexts and their behaviour within it, in order to obtain rich data and explore the research topic. To grant a comprehensive understanding of the police-community nexus under study, interviews were used as the primary source of data collection.

Following ethics approval by Carleton University's Research Ethics Board, oneon-one interviews were conducted with both police and community participants. All participants were recruited to participate in this study via a formal electronic mail that 
was sent to them in June of 2012. Written consent was obtained from both police and community participants, each one assured of the confidentiality of the information that would be discussed during the interviews and each one provided the opportunity to keep their identity anonymous throughout the study. As all participants opted to keep their identity anonymous, they were assigned pseudonyms to link their identity to their interviews, names that were only known to me.

Interviews were conducted in person and with the consent of participants, their interviews were audio recorded. The audio-recorded data provided two advantages, the ability to focus on the interview and probe further into discussions while minimizing any distractions that may have occurred from note-taking and the advantage of retrieving the data accurately and simply at any time (Crabtree \& Miller, 1999). While initially participants appeared uneasy about sharing their personal thoughts knowing they were recorded, they were quickly reassured that the recordings would only be accessible by me and that they would be provided the opportunity to review the transcripts that were generated from the audio-recordings to ensure that the information that was provided was admissible in this research and did not threaten their reputation in the community or professional status. The transcripts and audio-recordings were kept electronically (on both my personal laptop and a USB key) and were password protected. Electronic audiorecordings and transcripts of the interviews were subsequently deleted upon completion of this research.

The interviews that were conducted with both police and community participants followed a thematic interview guide that allowed me to conduct semi-structured, openended interviews. One of the key considerations in constructing the interview questions 
was that they would extract contextual knowledge and experiences based on important issues that were identified in the community policing literature. Care was taken to generate questions that followed a certain order to ensure questions flowed reasonably well and comprehensible language was used to formulate questions. The interviews provided participants with the flexibility to discuss issues they considered to be relevant to their situations while providing me with the flexibility to probe further into the participant's knowledge to seek clarification and elaboration or to obtain richer qualitative data.

\section{$\underline{\text { Review of secondary materials }}$}

The interviews were further supplemented with the analysis of secondary data that was obtained from both the Ottawa Police Service website and the Community Police Centre website (both of which are available to the public). The secondary documentation and data provided a fruitful ground to elicit how community-policing initiatives are implemented. This component of the case study involved reviewing the following documents:

- The Ontario Mobilization and Engagement Model of Community Policing: The Ontario Association of Chiefs of Police implemented a community-policing model to provide direction for police departments that are committed to community policing. The model attempts to provide officers with the skills and tactics to do community policing depending on the requirements of the neighbourhood.

- The Neighbourhood Watch "How to Get a Watch Going and Keep it Going" Handbook: The administrative guide was used to provide details on the Neighbourhood Watch program, specifically, to outline how was the program is marketed, how the program functions and to outline the roles of participants that are involved.

- The Community Police Centre Operations Guide: The guide, which is mainly intended for Community Police Officers, their supervisors and Community Police 
Centre volunteers, provides an outline of the philosophy and standard operating procedures for the Community Police Centres. The document was resourceful in understanding the operational strategies of the Community Police Centres in delivering community based policing and programs.

\subsection{Analytical Framework}

\section{Content analysis}

In order to investigate how community policing is translated into practice for the Ottawa Police Service and to consider how its operationalization influences the perceptions of the police and the community, a content analysis of the interview transcripts was undertaken. As described by Budd, Thorp and Donohew (1967), qualitative content analysis focuses on the characteristics of language as communication and underlines the contextual meaning derived from the text. Accordingly, based on the subjective interpretation of the data content, the text is then systematically classified through a process of coding of themes or patterns identification. Hsieh and Shannon (2005) identified three approaches that are used to interpret meaning from the content of text data: conventional, directed or summative. The major difference amongst them lies in the coding schemes, origins of codes and threats to trustworthiness.

The directed content analysis was guided by structured coding categories that were derived from key concepts and variables of the literature (Potter, Levine and Donnerstein, 1999). As the data for this research was primarily collected through interviews, open-ended questions were used to start, followed by targeted questions about the pre-determined categories (Budd, Thorp and Donohey, 1967). Based on the transcripts, the collected data was organized into the pre-determined codes and any text that emerged that could not be categorized into the coding scheme, was provided with a new code. The direct approach provided the framework to analyze how participants 
involved within the police-community nexus perceived community policing and the review of key materials as described in the previous sub-section, provided the analysis for considering how the police service claim to implement community policing.

The strength in employing a direct approach to content analysis is in the availability of prior research and theories to support or extend the data results (Hsieh and Shannon, 2005). However, while existing research and theories may give strength in supporting the data, it also poses as a limitation as researchers are approaching the data informed and thus with a strong bias. Approaching the data with a bias, in turn, contributes to the likelihood of finding more supportive evidence in the data then nonsupportive evidence. Secondly, participants answering probe questions may be indirectly guided by the cues of the researcher to answer in a specific way (Hsieh and Shannon, 2005). Furthermore, problems of inference and reliability threaten the research data, as the researcher may be influenced to draw conclusions about underlying theoretical constructs on the basis of a small segment of the interview transcript and in turn the intracoding may not be trustworthy (Titscher et al. 2000). In order to minimize bias and achieve neutral results, I attempted to construct questions and probing questions in an objective manner and provided the coding text to a peer researcher in order to ensure that the constructs being investigated are shared and would be applied in the same way by that researcher.

\subsection{Limitations of Case Study Research Methodology}

The use of case study research presents some limitations in relation to the quality of the design. Firstly, the main limitation of the case study research methodology lies in its external validity. Common concerns are that single case studies cannot establish the 
domain to which its findings can provide a basis for scientific generalizations (Yin, 1989). However, this research study did not conclude with broad generalizations to a population but rather based on the perceptions and insights of the actors involved in the police-community nexus, attempted to analytically generalize the findings to theoretical propositions (Yin, 1989, p.44).

Secondly, the construct validity of the case study is another element that may impact the quality of the research. Literature on the case study methodology highlights that a key issue is that researchers may potentially fail to develop a sufficient set of operational measures, therefore leaving the data collection and analysis to subjective judgments (Yin, 1989). In order to enhance the construct validity of this research project, multiple sources of evidence were used in the collection and analysis of the data. Special attention was paid to the selected secondary materials that were used in the data collection phase of this research. As indicated by Yin (1989), secondary sources have great value when used in conjunction with other sources of information; however caution must be exerted as these documents are publicly available and are informed by information and decisions that pertain to the specific social, economic and political context from which they are from (p.88). Therefore, in selecting the secondary material, attention was paid to the specific purposes that these documents were produced for along with the conditions under which they were produced and their designated audience.

Thirdly, reliability, referring to the ability for the research to be replicated, is a significant concern to the case study research. Specifically, the issue is that the case study design should be capable of being replicated if another researcher was to engage in the same project (Yin, 1989). With the objective of ensuring the reliability of this research, 
the procedures that were used to conduct this study were documented as thoroughly as possible. However, it is necessary to acknowledge that there was a general lack of standardization throughout the interview process. The quality of the interviews was contingent on the interchanges between the participants and myself. By recognizing that the interview is an emergent process and those participants vary significantly in the way they approach the interview and contribute, the way that questions were presented and the length of time that each respondent had to answer varied. Arguably, this may have affected the reliability of the data.

Overall, to achieve rigour and assure a level of reliability and credibility of this research, a process of triangulation was also utilized. Triangulation, referring to the process whereby multiple sources are considered to support one another and enrich the researcher's understanding of a phenomenon, was used with the participants involved in their research (Remenyi, 2012). Otherwise known as informant triangulation, using the method provided the opportunity to include and compare the individual perspectives and insights of the different actors within the police-community nexus under study.

\section{Conclusion}

This chapter provided an outline of the theoretical orientation and methodology that was employed to complete this research project. Divided into five sub-sections, the chapter first outlined the social constructionist approach was used to orient this project. The chapter then described the case study research methodology that was used for the design of this project, provided the sources of data that were collected for this study, followed by details on the analytical framework used to analyze the data, and concluded 
by describing some of the limitations pertaining to the quality of the research methodology. 


\section{CHAPTER FOUR}

\section{Tension One: The Conceptual Limitations of the "Community"}

As described in Chapter Two of this research, in neo-liberal practice, appeals to the community in crime prevention presupposes that communities have the capacity to mobilize their resources of social control. In community policing, the belief is that by working together, residents and the police can better assess concerns about crime in the community and reinforce their collective need for greater protection (Murphy, 1988). However, in the context of this research, the ambiguity over what and who constitutes the "community" proved to be limiting when considered in association with collaborative engagements such as community policing.

To demonstrate the conceptual tension of the "community", the following chapter presents the first theme that surfaced from the qualitative interviews with both police and community participants. The chapter first outlines the different ideological ways that police and community members understood the meaning of "community" and then considers the practical implications of the term. This chapter argues that the way in which both police and community participants negotiated the meaning of "community" had an impact on the way they considered community membership and representation in the Neighbourhood Watch program. Therefore, while the community policing philosophy seeks to build "meaningful" relations between the police and the community and establish inclusive processes, the reality for participants in this research is that community-policing practices have inadvertently led to new forms of exclusion. 


\subsection{Understanding "Community"}

The concept of "community" is frequently echoed in community policing resources for the Ottawa Police Service. As found in the community policing philosophy of the police department, the "community" is invoked in terms of a location but is also referred to as a partner for the police in crime prevention:

"Our Community Policing Philosophy is to move as rapidly as possible to include the community as an active partner in problem-solving and prevention and to re-assess the current community-based activities of the Ottawa Police, and to retain only those which advance progress in the achievement of the above priorities."

(Ottawa Police Service, 2013).

Thus to clarify what is meant by "community", police and community participants were asked to define the concept and to consider its application within the context of community policing and the Neighbourhood Watch program.

Amid the various discussions on what constitutes the "community", both police and community participants began constructing the term using geographical and social attributes. As a geographic space, the "community" was delineated in terms of physical and identifiable features, and as a social space was featured in terms of relationships. However, while all participants recognized the term "community" through tangible or relational characteristics, both groups of participants differed in the way they described those characteristics.

For community members, the composition of the "community" as a geographic space was recognized as a place. Pivotal to their conceptualization of the "community" as a place, was identifying elements of location: where they are and what and who surrounds them. Specifically, community participants identified the "community" using 
urban, suburban or rural attributes and markers such as street signs, parks and businesses.

As one community participant described:

In defining community, I would speak of it in terms of geography. A community is a group of people living close together within specific boundaries of a neighbourhood. For us in this suburban neighbourhood, there are many smaller communities and they are marked by street signs or identified with housing development names.

Community participants also used social markers or social space to distinguish communities. Thus, a "community" defined by social space was considered by participants as a network of individuals and groups that were committed to one another based on a common interest or shared values, norms and meanings:

But you see, the term community is more than just about geography and boundaries but also about people coming together united by a shared purpose, goal or interest. So for example, a community association or even a community Neighbourhood Watch, people are bound together by a common objective.

On the other hand, police members that considered the "community" as a geographic space used more eclectic terminology. Police participants considered the “community" as an organization of space determined through spatially defined jurisdictions, divisions and catchment areas. Communities were described as constitutes around the lines of divisions that were drawn by the organizational world of the police:

Within our organizational structure we have three divisions: Central East/West, West and Rural West and East and Rural East. Within each of these divisions, we have catchment areas, which are based on physical boundaries. The population living within that catchment area is the community we work with.

Police members also described the "community" using social characteristics. However, compared to the community participants that emphasized a commitment aspect of "community", police members identified the social "community" as being comprised of 
socio-economic groups, ethnic groups, marginalized groups or activist groups. As

expressed by one police participant, these social characteristics are bound together by a common thread:

We can also understand "community" as any group or collective of people that have a common thread. You can have the youth community, the senior community, the GLBTQQ (Gays, Lesbian, Bi-Sexual, Transgendered, Queer and Questioning) community, the Asian community etc.

The dominant discourse expressed by police and community participants assumed that community maintains elements of geographic and social characteristics. The differences between both groups of participants is that the way in which they negotiated those physical and social characteristics had an impact on how they applied the concept of community to community policing and the Neighbourhood Watch program.

For community participants, their hegemonic normative vision of "community" as a place and set of shared values appealed to the way they described the community in Neighbourhood Watch. In their discussion of the Neighbourhood Watch program community participants identified an experience dimension of the term community. The experience dimension of community that was echoed throughout interviews was described by participants as a "sense of community" and offered a more romantic view of the term that suggested a perceptual feature of familiarity, friendship and interdependence with others.

A "sense of community" in that regard relates to identification with that neighbourhood and associating oneself to that neighbourhood name. Secondly, sharing information and not being reluctant to do that and basically I guess people knowing each other and having a sense of knowing who that person is. 
The "sense of community" described by community participants was commensurate with the principles embedded within the Neighbourhood Watch rhetoric of "getting to know your neighbours" and the collective effort to reduce and prevent crime in their neighbourhoods (Ottawa Neighbourhood Watch, 2008). What community participants claimed to understand about "community" is that through the Neighbourhood Watch program and relationship with the Community Police Officer, the community could emerge as a means of reinforcing the virtues of cooperation and familiarity.

However, the police participants' ideological construction of the community in terms of divisions and groups bound by a common thread, led them to discuss the "community" primarily in terms of a policy instrument. Defining "community" as a policy instrument is reflective of a method by which organizations and agencies can minimize their problem solving, service delivery and financial responsibility for a given social need (Crawford, 1995). According to police participants, the cooperation of the community in community policing and the Neighbourhood Watch program was considered as beneficial in assisting the police about crime and criminals and legitimizing police actions in individual incidents. For police participants, the community offered the benefit of proximity to the local, and therefore it was believed that the communities possessed the most information about crime and were best suited to craft the strategies to identify and resolve local problems. As one police participant explained, the community has been promoted as a source of resource for the police organization, to which responsibility for aspects of crime control could be devolved:

I think it [Neighbourhood Watch] was a form of trying to reach out to the community. It was the easiest way, because it requires the least amount of effort administratively and you get the most "bang" for your buck. The neighbourhoods do a lot of the work. Crime prevention through 
Neighbourhood Watch is something that the officers can assist with formulating, but it is the Neighbourhood Watch Coordinators themselves that run the program and determine its success. We have a supporting role. The burden is not for us to run the program it is for us to reach out to the people and find the Coordinators that will make good community leaders and to establish the program in the neighbourhoods.

The rhetoric of "community" suggests that the way in which participants understood the concept impacted the way they were approaching the police-community partnership. While there was a consensus among both police and community participants that the term "community" maintained elements of physical and social space, their ideological understandings of the concept pulled in different directions at the practical level of community policing and the Neighbourhood Watch program. The claim does not suggest that the concept of community should have a fixed meaning, but rather is meant to demonstrate that the different understandings of the concept have led to conflicting values and expectations in community mobilization, a theme that will be further explored in Chapter Five of this research.

\subsection{Community Membership}

The way in which both police and community participants negotiated the meaning of "community" further impacted the way they understood community membership. Initially, both groups of participants acknowledged that membership in a community could be determined by two characteristics: being a resident of a community or participating in a community initiative.

When discussing residential membership to a community, community and police participants brought to the fore dimensions of geographic space, noting that membership within a community simply involved living within designated boundaries. Some community participants further added that residential membership to a community 
anchored place identity by providing its residents with a common identification to a specific community name. As one community participant expressed:

When you consider who's part of the community, it can really be anyone. It does not matter if you do not participate in community functions, the fact that you just live there, makes you part of that community. When someone asks you where do you live?, your answer has some kind of reference to that community name. So you see, we describe ourselves as part of a community.

Several participants noted that membership in a community could also be determined through the participatory roles of community members in collective engagements such as the Neighbourhood Watch program or the Community Association. When probed further to describe membership in the context of Neighbourhood Watch, participants identified criteria using the three key roles of the program: the Neighbourhood Watch Coordinator, the Neighbourhood Watch Block Captains and Neighbourhood Watch members. The Neighbourhood Watch program embodied a display site for members to foster a collective identity of the community based on individuals identifying themselves with the norms and values of the program. As one police participant highlighted:

I believe that membership to a community could also be about who is involved in working with community related initiatives. For example, we have the Neighbourhood Watch program, which has three important roles that have to be satisfied, the Coordinator position, the Block Captains and the actual Watch members. So basically, by being registered in the program, makes you part of that community and working for the benefit of that community.

However, central to their understanding of who was or who could be a member of a community, were claims of who was not. All participants' compositions of membership contained undertones of exclusion and were manifested when describing community membership within the context of community policing and the Neighbourhood Watch 
program. In their discussions on community membership, community participants made statements centered on "problem people", referring to individuals who did not belong to the community and/or that threatened member's "sense of community". The statements of exclusion were rhetorically accompanied by distinctive attributes that constituted "problem people". Participants identified "problem people" as individuals engaging in activities that were opposed to the norms of the community's social order. As one community participant articulated:

Vehicles that stop often in the community, people wandering late at night, people scouting out homes and lawns, groups of teenagers that linger out at night from other neighbourhoods and just generally people that look out of place from our neighbourhood... those are the kinds of things that we are looking out for. We know these people do not belong in our community, and by being vigilante we can protect each other from potential crime and keep our streets safe.

This element of exclusion can be attributed to the discourse found in Neighbourhood Watch promotional material, which encourages individuals and communities to protect themselves from perceived threats and/or individuals perceived as suspicious (Ottawa Neighbourhood Watch, 2008). Therefore, through the Neighbourhood Watch program, community participants assumed that members belonging to a community would gauge the moral and normative standards of the collective to eliminate, remove or ban "problem people".

Similarly, in discussing community membership, police participants also touched on elements of exclusion. According to police participants, in order to be considered a member for a Neighbourhood Watch, residents must satisfy specific criteria that have been established by the police department. These criteria are in place because eligibility to receive a Neighbourhood Watch street sign (a sign that identifies a specific locality as 
part of a Neighbourhood Watch) is dependent on them satisfying the requirements.

Commensurate with their conceptualization of the community as a policy instrument, police participants focused on community membership in terms of individuals bound together by the interest of participating in a program. As best captured by one police participant:

For people to be considered part of a Neighbourhood Watch they have to meet our requirements. We have some basic things that need to be satisfied. For example, a Neighbourhood Watch cannot receive a street sign identifying them as part of the Watch unless they have a certain subscription rate from the homes in their area.

Furthermore, in line with their discussions of community membership, police participants discussed the social composition of the neighbourhood, often emphasizing that it is comprised of both public and private housing. According to police participants, homeowners were more inclined to organize and sustain a Neighbourhood Watch, compared to the public housing residents. Police participants noted that in some cases, homeowner residents may view residents of public housing as the source of the community issues and thus, by creating a watch establish barriers between those involved in the program and those whom are not:

I find that homeowners are more likely to get together and form a Neighbourhood Watch then those residents living in the social housing community of this neighbourhood. I think this is because they [homeowners] have this sense of protecting their property and have access to more resources to get organized together to form the Watches. In social housing there is more resistance because no one wants to take the leadership role-you know "snitch mentality". Then on the other side of this, you have some homeowners who consider the source of community issues as stemming from the social housing community. So in a way, Neighbourhood Watch is used as way to protect the residents from the "outside" problems. 
In community policing, spatial attributes are recognized as critical variables because crime is defined in terms of area and locality (Crawford, 1995). In the case of the Neighbourhood Watch program, the spatial notion of crime prevention is exemplified via the Neighbourhood Watch street sign, which serves to recognize an area as a Neighbourhood Watch, define its boundaries and identify the number of participants involved within it. Such spatial features become problematic because, while the street signage may project an image that the community residents participating in the program are active citizens that are taking ownership of crime prevention and safety in their community, it also serves to exclude segments of the community by identify the residents that are not involved. Therefore, in an attempt to engage residents and bring them together, the Neighbourhood Watch signage may in turn potentially serve to exclude segments of the community. Furthermore, as confirmed in research by police scholars, the social composition of an area may influence community policing initiatives as community policing is susceptible to being adopted by the affluent white middle class, and thus may fail to penetrate areas that are less organized but yet most affected by crime (Skolnick \& Bayley, 1988, and Crawford, 1995).

\subsection{Community Leadership}

The unrepresentative feature of community membership further underscores the issue of legitimate local representation, as the community does not speak with "one voice" (Kelly \& Caputo, 2011, p.21). Within the hierarchical structure of the Neighbourhood Watch program is the role of the Neighbourhood Watch Coordinator. According to official Neighbourhood Watch promotional material, the Neighbourhood Watch Coordinator is responsible to represent Neighbourhood Watch members' interests 
and work in partnership with the Community Police Officer (Ottawa Neighbourhood Watch, 2008). Community and police participants were asked to describe how Coordinators were selected to represent and speak on behalf of other Neighbourhood Watch members.

As all community participants that were interviewed were active Neighbourhood Watch Coordinators in their local Neighbourhood Watches, participants focused on discussing how they became leaders. When challenged about their representative roles in the Neighbourhood Watch program, most community participants used similar responses, claiming that other Neighbourhood Watch Coordinators that were seeking to expand the program within the broader neighbourhood boundaries recruited them. When further asked how other Neighbourhood Watch Coordinators identified them as potential representatives, participants claimed that they had a relationship with those Coordinators through other community initiatives or interest groups. The usual justification that was provided by community participants was that their representativeness was ideal because they lived in the area, had first hand experience of it and knew the local people. As best expressed by one community participant:

A Coordinator from another Neighbourhood Watch sought me out. We knew each other from a community group that we are both part of. So one day she approached saying that they were looking to expand their Neighbourhood Watch and wanted to know if I would be interested in taking on the role of Coordinator. I think I was a good candidate for the job because I'm familiar with the area. I've been living here for 20 years. People know me, I know them.

When asked about community leadership, all police participants underscored an element of suitability. According to police participants, Neighbourhood Watch Coordinators had to fulfill specific criteria which they briefly identified as: a desire to 
participate, a connection to other community members, the time to engage in the program, the ability to be inclusive with other members and the ability to maintain active communication with both the Neighbourhood Watch members and the Community Police Officer. According to the police participants, if the program leaders were not suitable for the Coordinator position, then it ran the risk of damaging the effectiveness of a Neighbourhood Watch. Thus, in their attempts to organize a Neighbourhood Watch with community members, police participants claimed that they sought out representatives that "understood" the language and practice of crime prevention. As one police member identified:

Our job is to reach out to the people and find the Coordinators that will make good community leaders and that will establish the program within the neighbourhood. Programs like these [Neighbourhood Watch] are entirely dependent on the quality of people that run them. So if you don't get the right kind of person that is involved in their community and that is able to galvanize the other members of the community to run it, then you won't have a successful program.

The ability to organize and identify issues within a community is a key feature of attaining a voice in a community. As demonstrated often Neighbourhood Watch Coordinators are individuals that take on the leadership roles because they are either affiliated with another community group (i.e. the Community Association) or because they are actively sought out by Community Police Officers. In the case of community policing, this raises concerns over legitimate community leadership as these representatives tend to be drawn from a pool of participants that may have specific and limited interests within a locality and also have the capacity to get organized. Consequently, the Neighbourhood Watch program may fall victim to a form or "majoritarian legitimation", which only seeks the consent of the majority of those 
participating in the program (Crawford, 1995). As a result, solutions to community issues may be particularistic, as participants aim to achieve specific goals as they pertain to their own interests, without consideration for the ramifications for people in other neighbourhoods.

\section{Conclusion}

This chapter demonstrated that the different ideological ways that the police and the community constructed the concept of "community" impacted their understanding of community membership and community representation. At the practical level of community policing and the Neighbourhood Watch program, these various ideological understandings of community, community membership and community leadership, has resulted in a tension between what community policing espouses to do and what may actually be happening. Said differently, although the community policing philosophy is attempting to build "meaningful" relations between the police and the community and establish inclusive processes, the reality for participants in this research is that community-policing practices may be fostering new forms of exclusion. 


\section{CHAPTER FIVE}

\section{Tension Two: Mobilizing a Responsibilized Community}

The ideal of the Neighbourhood Watch program is that community residents come together as neighbours to identify crime issues and concerns and develop strategies to reduce and prevent those problems (Neighbourhood Watch Ottawa, 2008). The latter element implies a partnership with the police, whereby greater communication and collaboration ensues toward the aim of crime reduction and prevention. Through a process referred to as "community mobilization", the goal of Community Police Officers is to assist community residents to establish Neighbourhood Watches for the overall purpose of enhancing community cohesiveness and strengthening residents' control of their internal dynamics (Ottawa Police Service, 2013).

However, the results of the interviews with both police and community participants brought to the fore an underlying tension concerning community mobilization, what it means, and the roles of the individuals involved within it. To demonstrate this tension, the following chapter presents the second theme that resulted from the qualitative interviews with both police and community participants. First the chapter outlines the way in which the police and community participants understood community mobilization and their roles within it. The chapter then outlines some of the challenges and benefits that participants identified in mobilizing efforts. The chapter argues that both police and community participants have different understandings of their individual roles within the partnership, which in turn has impacted their expectations of one another and thus has led to challenges in effectively being able to engage in community mobilization. 


\subsection{Understanding Community Mobilization}

The term "community mobilization" is frequently used in Ottawa Police Service resources on community policing, however understanding the concept proved to be a challenge because the available resources did not thoroughly explain its elements. Moreover, sifting through the literature on community mobilization for crime prevention further underscored a gap in understanding the term, as scholars acknowledged that there is no single definition or theoretical framework for community mobilization (Jamieson, 2008).

Nonetheless, testimonies of interviews with police participants suggested that "community mobilization" referred to a strategy that is used to support the police in their community policing efforts. According to participants, the "Ontario Mobilization and Engagement Model of Community Policing", is a community mobilization model that is provided by the Ontario Association of Chiefs of Police and is used within the Ottawa Police Service to guide their initiatives. To the extent that participants could explain the model, they claimed that it provided a series of tactics and skills to assist officers in gaining local knowledge, establishing relationships with the community and engaging them in becoming active participants in crime reduction and prevention.

Drawing on the Neighbourhood Watch program as an example, one police participant was able to describe how the program is used as a mobilization strategy to connect with the community and increase the community's involvement in problem-oriented policing:

I guess a good way to explain community mobilization is by using the Neighbourhood Watch program as an example. Through the program, we as police are able to go into communities and establish a Neighbourhood Watch. We then have access to a set group of people that we can connect to for information about community issues and are able to work with them to develop what's needed to address those issues. Access to this group of 
people also proves beneficial when we need to get information out quickly to residents about a specific issue or person of interest that may be on our radar.

Community participants were not asked to describe what is meant by "community mobilization" but their understanding of the term emerged throughout their discussions on the Neighbourhood Watch program. Compared to police participants that described community mobilization as a strategy, community participants involved in the Neighbourhood Watch program made reference to it in terms of an outcome. For community participants, their answers indicated that they considered their involvement in the Neighbourhood Watch program to advance a broader vision of community safety and security. As expressed by all community participants, their role in the Neighbourhood Watch program, as Neighbourhood Watch Coordinators, is to engage with other community residents and encourage their participation in the crime prevention initiative. By mustering community members to participate in the program, the outcome can in turn mobilize community knowledge, disseminate information, address local issues and increase community solidarity. As cited by one community participant:

Essentially, I see Neighbourhoood Watch as a program for people to connect. As a Coordinator, I try my best to engage with people and get them excited about joining. I try to get them to see that this is for the better good of the neighbourhood. So its not a "snitch program", but actually its about being able to share information with each other and "look out" for each other. The more involvement we have the better flow there is in sharing/getting out information. At the end of the day, everyone is aware, informed and the community itself is looked after.

Whether speaking of community mobilization in terms of a strategy or outcome, both groups of participants recognized that the term was founded on a partnership. This partnership between the police and the community could be vaguely interpreted as a means of bringing together community and police resources through the crime prevention 
program to address community problems. Nevertheless, the different ways in which the police and the community spoke about community mobilization proved to be valuable in understanding how they identified their roles and expectations of one another within the partnership.

According to police participants, community residents engaging in the Neighbourhood Watch program were responsible for the organization, management and operations of their Neighbourhood Watch. Commensurate with the way in which they understood the community as a "policy instrument" in Chapter Four, police participants claimed that the role of the community in the Neighbourhood Watch program was to be "active participants" in the service delivery. For police members, active participation translated to having access to community residents that were involved in the crime prevention program, that could be relied on to organize community meetings, solicit the views and concerns of other community residents and that would maintain a flow of communication between the community and the police. The following quotation illustrates this point:

Neighbourhood Watch is one of the core crime prevention programs that we offer as a tool for a community that is interested in reducing and preventing crime in their area. We set up the community with the resources they need to run the Neighbourhood Watch, and then its up to them to maintain it and manage its operations. We as police expect the community to be active and committed participants in the program. Which is why there is that established hierarchy of roles. The Neighbourhood Watch Coordinators are elected to be that connection between the police and the community and are the ones that doing things like organizing community meetings, connecting with their neighbourhood, collecting information about the community issues and maintaining communication with us.

A common statement that police participants made was that the role of the police in the partnership is a supporting one and thus the expectation was that the community be 
heavily involved in the operations of the Neighbourhood Watch and dealing with their community issues. As taken from one police interview:

Community policing is about two things-the community and the police. We come to the table with our resources, but we also need the community to be actively involved with theirs. Community members that volunteer to participate in programs like Neighbourhood Watch and our other crime prevention programs need to be involved and we have to be able to rely on them to help us figure out what the issues are in a community, what needs to get done to address them in the best way possible and to keep us in the loop about things going on in the community.

Thus, police participants were advancing the view that they were engaging in a top-down approach to community policing, whereby the community was responsible for the program, and served as a source for the police to access for information or to use for their own information dissemination.

On the other hand, by considering community mobilization as an outcome, community participants depicted it in terms of a bottom-up approach. Closely linked to the way in which they defined the experience dimension of community in Chapter Four, community participants associated community mobilization with the overall good of the community's safety and security. It was believed that by gathering information about community issues and problems, the Neighbourhood Watch Coordinator could then channel the information to the police, and the police in turn would address them. So while community participants did recognize that their role was to coordinate the Neighbourhood Watches and liaise with community residents participating in the program, they considered the police as the source for solutions to their community issues. For that reason, community participants believed that alone, they did not have the capacity to sustain a crime prevention program such as Neighbourhood Watch and that 
the police rather than the community should be responsible for the Neighbourhood Watch program's direction and management:

The role of the police service in general as a support for resources. Not just financial and material resources, but also personnel resources and by that I mean the Community Police Officer. Myself and other members of the Watch expect a specific level of participation from the Community Police Officer. We appreciate seeing an officer who is involved, has presence in the community and who maintains that flow of communication, because I don't think communities have the capacity to maintain programs like Neighbourhood Watch alone.

Against this understanding of community mobilization, police and community participants advanced different views about what they considered were their roles in the partnership and what they expected of one another. For police participants, identifying community mobilization in terms of a strategy comports well with the ideology of neoliberalism and the discourse of "community responsibilization" (Garland, 2001). As resonated throughout the interviews with police participants, the Neighbourhood Watch program is considered as a mobilization strategy to encourage community residents to take ownership of crime problems in their neighbourhoods and to engage with police to share information pertaining to local matters. However, according to community participants, the community alone cannot organize effectively and they saw the police as uniquely responsible for ensuring the operations of the program. This discrepancy in roles and expectations has led to a tension in the partnership between the police and the community. While the tension between the police and the community is not a dramatic and overt one, it does amount to a conflict between what the Neighbourhood Watch program articulates and what is actually done. 


\subsection{Challenges of Mobilizing Efforts}

According to the Neighbourhood Watch program material, the program is designed to encourage the active participation of all community members and to facilitate the linking of resources between the community and the police service to reduce and prevent crime (Neighbourhood Watch Ottawa, 2008). However, despite the ideals of the program, community and police participants identified several challenges that they experienced in mobilizing efforts. These community mobilization challenges were expressed in various ways throughout the interviews with police and community participants.

For police participants, the most significant challenges were identified as community involvement and maintaining community interest in the Neighbourhood Watch program. According to police participants, predicators of community involvement in the program are difficult to disentangle because collaborative approaches with the community vary significantly depending on the local issues and other social factors. However, participants inferred that generally, people want to participate in the program, but do not have the time to take on leadership roles, such as that of a Neighbourhood Watch Coordinator. The struggle for police participants is to identify community residents that are willing and able to take on leadership roles and to encourage their participation in the program:

I think our biggest challenge is getting buy-in from the community. Everyone likes the idea of participating in the Neighbourhood Watch program and getting a nice sign that says "we are a Neighbourhoood Watch", but when it comes to the leadership roles of Coordinators and maintaining the active participation of residents-its tough. I think people are really immersed in their own family and work lives that at the end of 
the day, they don't really have time for this program. And time is so essential. So I think because of that we tend to see greater participation from retired community members, because they have more availability to devote to the program.

One police participant further added that the struggle to identify the "right people" to take on leadership roles in the program can be linked to police training. According to the police participant, the lack of training in the development of essential skills required when working with community members in collaborative approaches makes their job challenging, especially when it concerns identifying the individuals in the community who have the capacity to lead Neighbourhood Watches:

I think that part of the issue with community participation is finding the right people to join. You need people who fit a certain set of skills, that can manage the program and that have the time and energy to do it. One of the obstacles in achieving this is with our own officers. They don't get training on how to recognize those qualities.

Challenges concerning the participation of community members in the Neighbourhood Watch program were further amplified throughout interviews as police participants spoke about maintaining community interest in the program. According to police participants, collaborative engagements such as the Neighbourhood Watch program are often started in response to a specific incident and as a result it not unusual for interest to fade away once the program is started and the crime or community issues are resolved:

Neighbourhood Watches often start up because of an issue that the community experiences, like a home invasion, theft etc. So under those circumstances, people are really hyped up to join and there is a lot of interest. Once the Watch gets started and time goes on without any serious events happening in that community, it is very easy for interest in the program to slowly die down. 
Community participants also echoed similar challenges of community participation and sustaining community interest. Community participants often resisted the notion that they should bear the responsibility of organizing and maintaining the program. Participants remarked that interest in collaborative efforts with police fades away easily if the Community Police Officer does not have presence in the community, does not maintain ongoing communication with residents involved in the programs or does not provide resources or tools to support community members. Thus, participants believed that maintaining the interest of the community in crime prevention programming was the responsibility of the police. One community participant used the Neighbourhood Watch program as an example to illustrate how easy it is for participants to lose interest in the crime prevention program:

I think that it is very easy for people to lose interest in a program like Neighbourhood Watch. For the most part, I think it is fair to say that part of the excitement of joining the program is being able to say that you work with the police. But when the Community Police Officer is not around, or does not consistently maintain communication, I feel as though interest in the program really starts to diminish.

Community involvement in the Neighbourhood Watch program is based on the assumption that the community is willing and able to participate in the crime prevention program. The issue for police participants was not that the community did not want to participate but that the police were not creating the appropriate structures and processes to encourage meaningful interest. The result is a program that goes off course as communication between the police and the community is reduced and interest in the program fades away. 


\subsection{The Effectiveness of Mobilizing Initiatives}

Despite the challenges of community mobilization, when discussing community policing and the Neighbourhood Watch program, both police and community participants did have positive perceptions about the collaborative engagements. Police participants claimed that if operationalized under the right conditions, then community policing and the Neighbourhood Watch program can be effectively implemented. When probed further to discuss what was meant by "right conditions", all police participants referenced the active participation of community members, noting that when participants are engaged then proactive problem-solving approach can be effectively carried out. To demonstrate this, one police participant drew on an example of when effective communication and active participation of community members led to the successful mobilization:

We had fires in Orleans that were in a pathway for several years. During a certain time of the year we would have 3 or 4 fires in that area. Because the people in that area developed a good relationship with the officers, then at the beginning of the year we fanned out messages to them making them aware of that area in the pathway. So right off the bat they started going out monitoring the scene and we haven't had one this year. So it is one of those things, where you have to give them information and once you give them the information you have to give them feedback for the results. If they can see that it is working based on what you are doing then you are going to be successful. It is also a two way street for the organization.

Community participants equally spoke positively about community policing engagements, highlighting joint collaborations with the police as important and valuable. According to one community participant, working with the police in joint engagements has significantly increased the overall morale of the community's sense of safety. The participant claimed that the presence of the community police officer and the officer's genuine interest in working with the 
community members, made them feel a part of something important and as contributing the overall quality of life in their neighbourhood:

I think community policing is a great innovation. We have a great community police officer and the officer's participation and involvement in our community truly makes us feel proud to be part of Neighbourhood Watch and involved with the police service to better our community and prevent crime.

Creating the appropriate structures and processes to encourage community involvement and to sustain community interest is complex. Considerable thought has gone into understanding the individual roles of the police and the community in community policing. Under the rubric of community policing, the Neighbourhood Watch program is being used to establish partnerships between the police and the community, but what is believed to be missing is a realistic discussion about what this partnerships is meant to accomplish (Eck \& Rosenbaumn, 1994). As emphasized in the community policing literature, there are relatively few systematic evaluations of community policing programs (Skogan, 1994). Accordingly, the challenge for community policing is to establish a framework that would direct both police and community participants to be active participants in the partnership, and to be cognizant about what they can do and the time and resources they can devote to it.

\section{Conclusion}

As demonstrated in this chapter, there is an underlying tension in the police-community partnership about the individual roles and what they are expected to accomplish. Interviews with police and community participants revealed that the way in which they understood their roles and their expectations 
of one another differed significant. This discrepancy in roles and expectations has further led to challenges in effective community mobilization, namely, recruiting and sustaining participant interest in the Neighbourhood Watch program. 


\section{CHAPTER SIX}

\section{Tension Three: Conflicting Police Models}

The Ottawa Police Service operates as a paramilitary organization that is characterized by traditional hierarchical and bureaucratic police structure. As part of the centralized system police orders are distributed from the top-down, information flows from the bottom-up and record keeping is extensive. In contrast, community policing relies on a decentralized system that stimulates creativity and enhances the decisionmaking power of the community. In referring to this dichotomy of police models, police scholars often infer that the former traditional policing model is replaced by the alleged proactive approach of community policing (Murphy, 1988).

Thus, the second underlying tension within the police-community nexus involves the confrontation of paradigms between the reactive and the proactive approaches to policing. By presenting the third theme that resulted from of the qualitative interviews with both police and community participants, this chapter claims that in an attempt to operationalize community-policing initiatives, police participants are confronted by organizational structures and an underlying police occupational culture within the traditional police department apparatus that do not support community policing. The chapter argues that for the Ottawa Police Service, community policing has not replaced the "traditional" approach to policing, but rather exists within it. The result of this tension for police participants in this research is a ripple effect that impacts aspects of officer training, the promotional reward system and the way in which community policing is perceived across the police department. The ripple effect is also felt by community participants, who are challenged in working with Community Police Officers that are not 
familiar with the Neighbourhood Watch program or confident in their abilities to engage with community members in community policing.

\subsection{Police Organizational Structure}

\section{Accommodating proactive policing in a traditional police structure}

In exploring the extent to which the police department under study implements community policing, police participants agreed that the organizational transformations were best demonstrated through the department's official philosophy on community policing and enacted through the Community Policing Unit and personnel.

Firstly, participants acknowledged the Ottawa Police Service's commitment to community policing as a requirement mandated by the Ontario Association of Chiefs of Police (OACP). A central feature of the OACP community policing initiative involves establishing mechanisms that would contribute to the development of a partnership between the police and the community in crime prevention and community safety (Ontario Ministry of the Solicitor General, 2010). According to police participants, police organizations often implement community policing using community and crime prevention programs that are designed to enhance the police service's visibility and establish a connection with the community. However as one police participant mentioned, since there are no standards to measure the success or failure of community policing, the extent of community policing practices vary considerably across the province.

Nonetheless, participants advocated that an organizational philosophy is a central ingredient that is necessary for community policing to function as it would provide a strategic direction on community-policing activities for both police agency members and 
the community. For the Ottawa Police Service, the organizational philosophy for community policing was described by one police participant as a service delivery model that espouses the implementation of problem-oriented policing and includes the community as an active participant in crime prevention:

Police services in Ontario are mandated to have community policing and crime prevention programs as their core functions. In this police department our community policing mission is to encourage the community and our officers to work together in collaboration when dealing with crime and other community issues. So basically, through our crime prevention programs we want to provide an opportunity for police to increase their involvement with the community, partner with them to identify some of the issues that are going on [in their communities] and consult them on the solutions or steps that are needed to address those issues. We call this problem-oriented policing.

By comparison, one police participant claimed that while the police department has an official community policing philosophy, it is both ambiguous and vague. The officer argued that the department's philosophy did not provide a clear conceptualization of what community policing entails and how it coincides with a community's demand for service. In addition, the officer noted that the department's wooly philosophy is even more evident in the way that police members themselves could not clearly articulate it:

We have a community policing philosophy, but officially I couldn't even tell you what it is. I think the same goes for many officers here. It is a pretty vague philosophy with no clear outline of what our role is as officers, what the role of the community and what the relationship is between the police and the community. So I guess in a way, we all operate with our own ideas about community policing...

Participants described the Community Policing Unit as central to the function of problem-oriented policing. Unlike traditional policing, the Community Policing Unit is decentralized, both in terms of its physical and authoritative characteristics. Physical decentralization refers to the Community Police Centres, described by police participants 
as the hub for community policing initiatives and the primary location for the operation of core crime prevention programs. Centres are located locally within the City's neighbourhoods and thus provide police officers with the flexibility to deliver the crime prevention programs and tailor them to the local context:

I think that when you form collaboration with a community, the point is that you need to be flexibility to accommodate the needs of the community. So the situation and issues in one community are not necessarily the same in another and even more, what is going on in let's say in the West of the City, could be a different issue than in the East. But we have these crime prevention programs that can be used to help build the partnerships that we need to build and we have the flexibility to adjust our services to fit the communities we are working with. It also helps that our Community Police Centres are scattered across the City, that allows for more effective engagement with the communities we are working with.

More importantly when discussing the decentralized approach of community policing, police participants also referred to the role of the Community Police Officer. As the central authority for the Community Police Centre, the Community Police Officer is responsible for the management and operations of the centre, including the centre volunteers, the financial budget and the crime prevention initiatives. Participants remarked that the role of the Community Police Officer necessitates greater agency and autonomy in key-decision making involving the management and operations of Community Police Centres, an authorization that is accepted by senior management.

There was a general indication among police participants that the police department's civilianization process was also a contributing factor to the decentralization of community policing. The process of civilianization is one whereby civilian personnel are hired and tasked to perform certain duties that contribute to community policing ideals. In the case of the police department, a Community Development Section, staffed by civilian Community Developers, are dedicated to work closely with Community 
Police Officers. As expressed by one police participant, in line with the Community Developers forte and understanding of community building practices, they are recognized as essential to supporting the community policing initiatives as they work to generate closer ties with the community and other community agencies.

\section{Structural obstacles in community policing reforms}

Whilst there is a collective acknowledgment that the police department is committed to community policing, police participants noted a concern about the police department's capacity to sustain the community-policing model. At the core of their discussions, police participants remarked that the successes of community-policing initiatives are dependent on the degree to which they are supported by changes in the administration of a police organization. In the context of the Ottawa Police Service, a common theme that surfaced during police interviews was the department's attempt to operationalize a proactive strategy of policing within a traditional administrative policing structure. For police participants, the gap between the police department's organizational and administrative arrangements to implement and support community-policing was unearthed in their discussions on the available training for Community Police Officers and the standards used to evaluate officers for productivity and promotions.

One of the much discussed challenges for police participants was the lack of a comprehensive in-depth training for officers appointed to the Community Policing Unit, both operationally in assisting officers to adopt a different policing approach, and administratively in the acquisition of the necessary skills to manage Community Police Centres. At the operational level, Community Police Officers are tasked with the role of engaging in specific practices of problem solving and community engagement, an 
approach to policing that demands skills that are not conventionally needed in traditional policing. The requisite for training police officers transitioning from the central mode of delivering policing to the proactive approach of policing was well understood by police participants. According to participants, the overall training that they received was in reactive policing, a style of policing that favours action-oriented responses to crime and that involves encounters with the public that are based on incidents, momentary connections and the containment of problems. Alternatively, in community policing, the role of the police officer is one that supports a proactive approach to policing, whereby Community Police Officers engage in specific practices of problem solving, relationship building and interactions with the community that are based on long-term connections. The lack of formal training in proactive policing for Community Police Officers was therefore believed to impact the officer's knowledge and expertise in problem solving, relationship building and community engagement as they would have to rely on the incompatible methods acquired in their action-oriented training. As one officer summarized:

Community policing is one of the few positions where you get the opportunity to build relationships, partnerships and trust with the community. In patrol for example, the interactions you have with people are very quick and quite often in a moment of crisis. Often too, you are not developing that long-term type of commitment and the relationship you have with a community when you are on patrol is one where you do not trust anyone. In community policing once of the first things you have to learn is to trust. But when you become a community police officer, there is no training so you say to yourself, "I will just use the skills that got me here". But the skills that got you here are not going to work in this kind of environment, where it is not enforcement suppression and is a proactive style of policing.

Along with the challenges of operational training, police participants also identified an administrative challenge when transitioning into community policing roles. 
From the primary delivery locations of the crime prevention programs that are offered by the police department, Community Police Officers are responsible for managing the daily operations of the Centres and placing a premium on developing partnerships with their communities through those programs. From the perspective of police participants, the police department's expectations of delivering community policing went beyond the current knowledge capacity of most officers within the organization. Participants were not implying that officers could not $d o$ community policing, but that the position required an understanding of community policing principles, knowledge of the crime prevention programs and basic management skills to operate the Community Police Centre. In the absence of essential training in the administration of the centres and the available programs, police participants claimed that the collective effect was a system that heavily depended on officers who did not have a clear understanding of the community policing objectives and strategies, their new roles in relation to the community, nor the community's role in participating in the programs.

When probed further on how police participants themselves transitioned into their community policing roles, participants noted that training was either informally done through job-shadowing of other Community Police Officers or by a civilian member from the Community Development Section. However, as indicated by one participant, for the most part, the lack of official training exacerbated frustration, resentment and aimlessness for officers forced to learn a different approach to policing:

We enter these roles with basically no official training. A lot of the stuff I learnt was self-initiated. I had to familiarize myself with the programs we offer, how they operate, what the role of the community is, and what my role is. It took me a really long time to get into the community-policing swing of things-because I had to learn everything myself. So by the time you get to a point that you are comfortable with the programs and the 
community, your time in the Unit is pretty much up. It is pretty frustration and there are times when you just feel like what's the point?

While community participants were unaware that formal training was not implemented for Community Police Officers, throughout their interviews, some community participants were critical of the police officers' capacity to engage in community oriented policing and questioned whether training was made available for officers transitioning into community policing roles. Participants noted that in the context of Neighbourhood Watch, a program that is based on the active participation of the community and the police, when a new officer enters the Community Police Centre, there is a profound impact on the effectiveness and efficiency of the program. Specifically, participants recognized that some police officers' knowledge of the Neighbourhood Watch program and comfort level when interacting and engaging with community members was minimal and that it often required a period of time for officers to adjust to the new position and the needs of the communities being served. As one community participant explained, the Neighbourhood Watch program could be characterized as a vulnerable organization that is only as strong as its weakest link, referring to the impact that a new officer can have on the whole function of the program:

The other core thought I have about Neighbourhood Watch is that it is an organization that is particularly vulnerable, because it is only as strong as its weakest link at any given level....Every level is critical and if any single individual doesn't function, then the area is in trouble...Doesn't matter how good the Community Police Officer is, it takes them time to get up to speed and know the program. What training does an officer get? What are the expectations?

Overall, when asked to describe what training should be available to police officers transitioning into community policing, police participants claimed that training needed to reflect a balance of the police department's community policing priorities 
infused with skills training in management and community development. Community participants further added that considering the nature of community policing, training should also incorporate innovative strategies that inculcate the input of the community, an approach that community participants claimed would contribute to creating the necessary symbiosis between the police and the communities they serve.

Adjunct to their discussions on training, police participants also argued that the broad policing ideology of enforcement was also embedded in the assessment systems used to evaluate the performance standards and productivity of officers. According to police participants, training in Police College instilled a centrality in the police emphasis on the number of traffic tickets that are issued, arrests made and registered street checks. An officer's entire career in policing then becomes dependent on the production of crime figures as what is needed to secure a place in a specialty unit within the police department or a promotion is based on the quantity and quality of their charges. As one police participant described:

My superiors look at the number of street checks, tickets and number of charges. They are trying to measure my ability to be a community police officer based on my ability to be an enforcement suppression officer. Looking at my own career history, as a patrol officer, I had about less than 5 criminal code charges, a dozen tickets and a handful of street checks. Looking at that, I thought to myself... that really does not make me look too good. But then I realized that makes me the best kind of Community Police Officer, because I do not believe in enforcement suppression. In some ways that is what I find as challenging with this role in this police department. What made you good on the Tactical Team or the Guns and Gangs Team, might not make you a good Community Police Officer.

The critical issue for police participants was that the quantitative bent used to evaluate the performance of police officers does not provide the necessary indicators to assess community police work. In justifying their concerns, police participants claimed that 
within the complex social structures of communities and their varying normative patterns, evaluations that rely on statistical assessments ignores the community policing objectives and distorts the job as officers focus on fulfilling the statistical expectations set by their superiors rather than focusing on the needs of the community and forging relationships with residents.

In discussing the mechanisms used to evaluate the performance of police officers, police participants also claimed that the pressure to fulfill arbitrary quotas risked having a profound impact on the relationship between the police and the community. As described by police participants, the partnership between the police and the community is forged on positive relations and trust, the challenge in issuing traffic tickets and making arrests ignores the discretion of officers and disrupts their community policing objectives:

So basically, they tell us, go build positive relationships with the community, go do proactive policing etc. But when it comes to our evaluations and even being considered for a promotion, the first thing they look at-is our numbers. How many arrests we made, street checks, traffic stops etc. So here we are, supposed to be the face of the community, but at the same time, practice enforcement?

In line with the productivity measures used to evaluate police officers, police participants noted that the statistical performance indicators required to be considered for future positions within the police department heavily impacted police officers' interests in joining the Community Policing Unit. Participants claimed that joining the Community Policing Unit was viewed among officers as a negative career move because upon completion of their term within the Community Policing Unit, officers were generally transferred back to patrol, rather than to a specialty unit or promotional rank. One senior officer also added that the career impact for joining the Community Policing Unit further influenced the "type" of officer that were attracted to the community-policing roles. As 
the officer explained, rather than joining the Community Policing Unit out of general interest in community work, some officers request to be assigned to community policing because of the flexibility in the position and stability in the working hours:

I think that one of the disadvantages that we have in the Community Police Officer position is that it is the kind of position that is not operational or investigative. So the opportunities that the officers see for themselves later after being there are minimal. At the present time, the officers that go to the Community Police Centres do not see it as an exceptionally good career move for advancement into the tenure process. Because the way it is set up, they are bumped back into patrol before they can go to other sections. So the officers that go there tend to go there for a lot of different reasons, but maybe not necessarily because they make really good Community Police Officers. We have a lot of good Community Police Officers...don't get me wrong, but there are some officers that go into those positions perhaps because it is a day shift job or because there is more flexibility etc. However, they may not necessarily be the type that are open to that type of a community environment. So it is a catch 22 sometimes. It is what it is. But I think you have to create a different type of criteria and different opportunities for the officers that go there to attract the officers you want to be in those positions.

The challenge for police officers is that much of what constitutes traditional

policing and the way in which police officers deal with problems is incompatible with the proactive requirements of community policing. Police values and ideologies are inscribed features of a police organization and are embedded in police working practices (McConville \& Shepherd, 1992). Police participants constructed an image of the Ottawa Police Service as heavily invested in the traditional model of policing. This traditional approach to policing significantly challenges community police officers' as it does not create the necessary environment that is conducive to encourage officers' motivation to engage in community policing, nor does it provide them with the appropriate tools to employ creative problem solving techniques. Nonetheless, a commitment to community policing does not suggest that it cannot survive within the conditions of a traditional 
police structure, but rather that informal support structures, isolated regulations and performance standards for police officers are required within the organization to sustain it (Wilkinson \& Rosenbaum, 1994).

\subsection{Police Occupational Culture}

Proactive policing as "real" policing

The analysis of the statements made during the interviews with police participants further suggested that the underlying police culture is closely linked and mutually reinforced by the organizational structure of the police department. In addition to their discussion on the police organizational structure, police participants also emphasized the police department's predisposition towards a common police culture as a central underlying issue to the implementation of community policing. The collective sense among police participants was that the police culture is underpinned by officers' understanding of their social world and their role as police agents within it. Specifically, participants explained that the police officer's perception of the relationship between crime, the public, and policing contributed to their resistance towards proactive community policing.

The officers' understanding of crime, the public and policing can be assessed by analyzing what they consider as appropriate responses to criminal behaviour. Since police officers conceptualize crime as a legally defined behaviour rooted in the criminal law, they in turn respond with legally defined responses. This definition also considers crime as an intentional act that violates prevailing norms in society and that require an immediate response from the police agency. Thus police consider reactive responses such 
as laying criminal charges and detainment as necessary deterrents to minimize the likelihood of future offending. As explained by one police participant:

For you to understand police culture, you have to understand how police view crime, society and their roles as police officers. You see crime happens when a law is broken and the police are called upon to respond to this violation. The way that police officers recognize the appropriate response to crime is through the reaction of laying a charge, arresting the offender and detaining them.

In turn, police participants described officers' normative understanding of crime as essential to how police perceive the role of the public. Although citizens are considered partners in the "fight against crime" police engagement with the public is solely based on calls for service. Relationships between the community and officers do not commonly develop because they are limited to the specific situation to which they have been summoned. However, police participants also noted that officers' predominant contact with the minority of the public engaging in criminal activity and deviant behaviour, accounts for much of their cynical views of society. As a result, even though police depend on the tacit support of the community to respond to criminal acts, operational encounters with the public also serve to reinforce a mentality that communities are inherently criminal and deviant. Thus, it is necessary for officers to retain their impartiality and distance from the community. As one police participant summarized:

Community members have an important role to help us as police identify where a crime has occurred. Without them, we wouldn't know when a crime has happened. But at the same time, the majority of an officer's interactions with the public are negative. We respond to calls for service when something bad has happened or a crime has been committed. So we are generally dealing with only about 5\% of the population. There is a bit of a contradiction there, since while we serve the public we are also policing the public. So basically, you wouldn't necessarily have a patrol officer going into the community and engaging with residents, because 
they have to protect citizens and at the same time not be overly familiar to them and potentially bias their response to incidents or situations in those communities.

Police officers' understanding of crime and their perception of the public presuppose the essence of policing as action-centered. Officers used the notion of "authentic policing" to define their sense of duty when describing their roles as police agents. The virtues of an authentic policing are embedded in a prevailing belief that police officers are "real crime fighters" and that crime-control is a public demand. The notion of authentic policing is characterized by the arrests of criminals, speeding when driving a police car and the excitement and adrenaline rush of going to calls for service. This experience is epitomized by the impositions of control and authority in encounters with citizens:

When a person signs up to be a police officer, they are most likely attracted to the position based on what they see on television, the "Dirty Harry" image of a police officer fighting crime, speeding to the calls, lights blaring, arrests made-just plain action. That is the image most people, including police officers, have of police work. It's about the "real crime fighters". Any cop will tell you that they became a cop for the promise of the cruiser, the uniform and the powerful image associated with being a police officer. There is this sense of authority and control when dealing with the public-these characteristics are part of the image of what real policing is. And like I said, Hollywood doesn't make movies about community police officers.

Police participants contrasted the ideals of community policing, noting that the proactive genre of policing was considered mundane and not valued by most police officers. Overall, community policing did not embody authentic policing as the cornerstone of its proactive approach places greater emphasis on the engagement of the public as a partner and more importantly, the prevention of crime. One police participant 
claimed that community policing is fabricated among officers as a "soft" approach to policing due to its non-sensational method to address crime:

I would almost say that Community Police Officers are considered to not be "real police", because we are the 1\% that is going in a different direction. When the organization develops its culture, it leans towards enforcement suppression. For example, if there is a gang spike, the answer is to put more money into guns and gangs. Maybe the answer is that we just need to go the other direction. I find with community policing, we are thinking way outside the box and we are trying to solve issues in the communities without press releases having to be issued and with victories that are done in a non-sensational way.

When police participants were asked to consider what constitutes the building blocks of police culture, participants linked it to the mutually reinforcing internal solidarity and social isolation that characterize "authentic" police work. In response to the internal solidarity and isolating nature of police work, involving shifts and the pressure of public scrutiny, participants described a process of unification and commonality that develops through shared stressful and dangerous experiences. Therefore through work associated norms police officers convey loyalty to colleagues and share a network of codes and standards that are used socialize new members. As best described by one participant, in order to maintain acquiescence into group norms, the common tendency among police officers is to socialize new recruits the moment they enter the police department:

The moment a new recruit enters the department they are socialized into this police culture. Don't get me wrong, it isn't something that you acquire instantly, but it is something that you develop overtime. I'll give you an example, when officers go to a call, there some level of agreement among them as to what the "appropriate" action is. This is based on our common values and beliefs of what policing involves. Also the experiences we have during those specific calls are pretty unique in terms of their level of stress or danger. So there is a great bond that develops among officers as they experience these situations together. And of course there is the long hours 
and shifts that officers work, so they tend to be separated form the public and you'll see more of them confining themselves to their working circles.

One police participant noted that officers have the capacity to resist the dominant police culture. The participant claimed that the isolation of community police work from other units aided officers who were dedicated to the proactive model to resist the internal pressures of conforming to a culture with which they disagreed. The participant further commented that regardless of the beliefs and philosophies underpinning the police culture, change in the overall police orthodoxy would have to start with the values espoused by the management. Recognizing that the leadership of a police department has an impact on the lower ranks, the participant argued:

It calls from leadership. If a chief is excited about community work and community policing, then it will rub off on the rest of the force and the image and culture stuff will follow. But when you have a police force that recognizes there are no bells and whistles in community police work, then they [the officers] will not be very attracted to the position nor will they buy into the ideologies. It's kind of like when you sell your car. You take the time to wash it, clean it, wax etc for the owner. You hand it to the owner all nice and shiny and they are just as excited about it then you were. But if you sold your car and just handed it to the next person all banged up and dirty, obviously that person isn't going to appreciate it. It is the same with community police work. If we value the centres, the resources put in and the position of the officer, then when the next community police officer steps in, they will value the role as well.

Police scholars claim that greater involvement from police officers in the development of the community policing concept is paramount to overcome police resistance. The goals of community policing are more likely to be adopted and accepted, if shared by the individuals responsible to operationalize their function (Bayley, 1993). Ergo, including the input of police officers in the development of community policing would offer police management the opportunity to be cognizant of the conditions under which the police officers are currently subjected to and at the same time, would cultivate 
a level of commitment and increase support by the officers as they would be invested in the implementation plans (Walker \& Walker, 1993). Additionally, ensuring that consultation with officers continues throughout the implementation and operationalization of the community-policing concept is essential. This consultation with police officers is necessary as it would ensure that community-policing objectives are relevant to the changing needs of society and demands placed on police officers (Loree, 1993).

\section{Conclusion}

This chapter outlined two themes that emerged during interviews with police and community participants: the police organizational structure and the police occupational culture. The chapter sought to demonstrate that in their attempt to operationalize community policing, the Ottawa Police Service are faced with a tension when operating a community policing within a traditional police structure. As highlighted by police and participants the result of this tension for police participants is a ripple effect that impacts aspects of officer training, the promotional reward system and the way in which community policing is perceived across the police department. The ripple effect is also experienced by community participants that reported a challenge in working with Community Police Officers that are not experienced in the Neighbourhood Watch program or community policing. 


\section{CHAPTER SEVEN}

\section{Conclusion}

As demonstrated in Chapter Two of this research, within the theoretical context of neo-liberalism, it was established that in an attempt to minimize its role in social control, the state has increasingly sought to transfer responsibility for it back onto the community. Community policing espouses a policing model that deviates from the imposition of social control towards a service delivery model that claims to recognize the needs of the community and encourage the expansion of partnerships between the police and the community (Crawford, 1998). This case study research focused on considering how the Ottawa Police Service operationalizes community policing. Within the scope of the study, the research also considered how the police and the community perceived the benefits and challenges of community policing. The research employed a social constructionist approach to examine the way in which police and community claimsmakers, advance their claims about how they typify, define or construct community policing.

The interview results with both police and community participants revealed that several components of community policing are operationalized within the Ottawa Police Service, including a community policing philosophy, decentralized Community Police Centres and community mobilization strategies such as the Neighbourhood Watch program. While the Ottawa Police Service has demonstrated a level of commitment to community policing, the research revealed that despite the ideals of community policing, three reinforcing tensions exist for both the police and the community. While each of 
these tensions exists independently of one another, together they impact the way in which community policing is being operationalized in Ottawa.

The first identified tension was revealed as police and community participants discussed the way in which they understood the "community" in community policing and the Neighbourhood Watch program. While the community considered their involvement in the Neighbourhood Watch program as an opportunity to improve their "sense of community" and enhance their neighbourhood, the police considered the community as an instrument and resource to gain greater intelligence on community issues and concerns. Closely linked to the first tension, was the second tension, which was uncovered as participants touched on the theme of community mobilization. The outcome of the interviews suggested that the different ways in which the police and the community understood the "community" in community policing and the Neighbourhood Watch program, further impacted their understanding of the roles and expectations of one another in the partnership. The effect of this discrepancy in roles and expectations led to challenges that were experienced in mobilizing efforts, including maintaining and sustaining active participation in the partnership.

Finally, the third tension that was uncovered became apparent as participants discussed the way in which community policing is accommodated within the traditional organizational structure of the Ottawa Police Service. The results established that the current organizational structure of the police department could not effectively sustain community-policing reforms. The consequence of this tension is a ripple effect that has impacted aspects of officer training, the promotional reward system and the way in which community policing is perceived across the police department. The ripple effect is also 
felt by community participants in mobilization efforts as participants are challenged to work with Community Police Officers that are not familiar with community policing principles or the Neighbourhood Watch program.

Although interview participants did perceive the partnership between the police and the community as important and valuable, the challenges identified in the interviews far outweighed the positives. Accordingly, going forward, the Ottawa Police Service is confronted by three challenges to encourage the development of community policing in Ottawa.

The first and main challenge for the Ottawa Police Service is to implement community policing in a systematic way across the police department. At the time this research was conducted, the Ottawa Police Service concentrated community-policing efforts within the Community Police Centres. However, it is important that the police service recognize that community policing is not a singular concept and that efforts be made to infuse the philosophy across the department and be part of its daily operations (Trojanowicz \& Bucqueroux, 1990). The plurality of conceptual understandings of community policing raises concerns about the capacity of the paradigm to deliver on its purposes, and therefore, articulable criteria must be used in order to define the limits of community policing, including the ambiguous understanding of who comprises the "community" and what constitutes their role (Eck \& Rosenbaum, 1994).

The second challenge is sustaining community-policing approaches for police officers. To sustain community-policing approaches, the Ottawa Police Service should consider dedicating additional organizational resources to community policing including, developing a training framework on community policing for police officers and 
implementing an appropriate reward system for Community Police Officers to mirror the proactive style required in community policing (Bayley, 1993). While many scholars have identified the issue of training for community police officers, a gap in the literature exists concerning an appropriate model to optimally train police officers involved in community policing (Eck \& Rosenbaum, 1994). Nonetheless, police scholars have suggested some changes to the training curricula of police officers, most prominently the development of training in problem identification, program development and evaluation and the management of community groups and resources (Roberg, 1994). Training in educational experiences that focus on community policing have also been suggested for the entire police department. Resistance to change is often a result of ignorance about a program or approach and therefore a knowledge component delivered across the department in a clear and comprehensive fashion would provide officers with an understanding of community policing, its purpose and its anticipated function (Seagrave, 1985).

Furthermore, a strong pervasive element that sustains the police culture is the reward system of the police department. Promotion to the next rank is a career goal for the majority of police officers within a police department. The implementation of a proactive approach such as community policing does not produce the same performance measures as reactive approaches to policing. Research supports the claim that the reward system significantly reflects the work orientation and beliefs of officers (Loree, 1993). Therefore in order to reinforce and invigorate police culture, the police reward and promotional systems should reflect and be in harmony with community policing ideals. To create a positive image of the community policing career stream, police managers 
should consider developing broader assessment indicators and tools that are relevant to community policing work (Loree, 1993).

Finally, the third challenge is developing appropriate evaluation criteria for community policing in order to effectively determine what it is meant to accomplish. Launching ambitious community policing effort, such as the Neighbourhood Watch program, will not be successful without establishing an evaluative framework based on means and ends (Murphy, 1988). Currently, the Ottawa Police Service has no evaluation guidelines to measure the success or failure of community policing initiatives and programs. In order to uphold accountability, the police department should therefore consider identifying key priorities of community policing and its programs with the community and periodically evaluate those priorities.

\subsection{Recommendations for Future Research}

While police scholars have speculated about the types of structures and strategies required to implement community-based initiatives successfully, there is little consensus in the reform discourse that underlines the importance of specific changes and specifically how they should be implemented to meet the future changing needs of both the community and the police or that acknowledge the expanding role of police officers in post-modern society. The Canadian police landscape is changing due to both internal factors within the police organization and external social factors. Police organizations are increasingly being challenged with decreases in operational budgets, increased demands from the public, the emergence of new and complex crimes and the constant threat of cross-border terrorism. Collaborative approaches are thus essential in assisting police organizations to meet the future needs of society. Accordingly, future research should 
consider the possibilities of an integrative framework for community policing, one that considers the necessary structures and systems that are required to implement community policing effectively and efficiently and that simultaneously ensures that collaborative approaches between the police and the community are based on common values. The value of the research would be in establishing a sustainable and integrative framework that would shape the future direction of community policing practices and utilize police services and resources effectively. 


\section{REFERENCES}

Bayley, D.H. (1988). “Community Policing: A report from the Devil's Advocate”. In Greene, J.R and Mastrofski, S.D. (Eds.), Community policing: Rhetoric or reality?. New York: Praeger.

Bayley, D.H. (1993). Strategy. In Chacko, J., \& Nancoo, S.E. (Eds.), Community policing in Canada (p. 39-47). Toronto: Canadian Scholars' Press Inc.

Beck,U. (1992). Risk society. London, England: Sage Publications.

Berger, P.L., \& Luckmann, T. (1967). The social construction of reality: A treatise in the sociology of knowledge. New York: Doubleday.

Budd, R.W., Thorp, R.K., \& Donehew, L. (1967). Content analysis of communications. New York: Macmillan.

Buerger, M. (1994). The Limits of Community. In Rosembaum, D. (Ed.), The challenge of community policing:Testing the promises (p.270-274). Thousand Oaks, CA: Sage Publications.

Cohen, S. (1985). Visions of social control: Crime, punishment and classification. Oxford, England: Polity Press.

Cooley, D. (2005). Introduction:Re-imaginging policing in Canada. In Cooley, D. (Ed.), Re-imagining policing in Canada. Toronto: Toronto University Press.

Crabtree, B., \& Miller, W. (1999). Doing qualitative research. London:Sage Publications.

Crawford, A. (1995). Appeals to community and crime prevention. Crime, Law and Social Change, 22, 97-126.

Eck, J., \& Rosenbaum, D. (1994). The New Police Order: Effectiveness, equity and efficiency in community policing. In Rosembaum, D. (Ed.), The challenge of community policing: Testing the promises (p.3-21). Thousand Oaks, CA: Sage Publications.

Etzioni, A. (1997). The new golden rule:Community and morality in a democratic society. London: Profile.

Friedmann, R. (1992). Community policing. Hertfordshire: Harvester Wheatsheaf. 
Friedmann, R. (1994). The Community Role in Community Policing. In Rosembaum, D. (Ed.), The challenge of community policing: Testing the promises (p.263-270). Thousand Oaks, CA: Sage Publications.

Garland, D. (2001). The culture of control:Crime and social order in contemporary society. Chicago: The University of Chicago Press.

Goldstein, H. (1987). Towards Community-Oriented Policing: Potential, basic and threshold questions. Crime and Delinquency, 33 (1), 6-30.

Goldstein, H. (1990). Problem Oriented Policing. New York: McGraw-Hill.

Gordner, G. (1996). Community Policing: Principles and elements. US Department of Justice. Retrieved on February 2013. From

http://www.nodsv.org/images/communitypolicingprincipleselements.pdf.

Greene, J.R., \& Mastrofski, S.D. (1985). Community policing: Rhetoric or reality. New York: Praeger.

Guba, E.G., \& Lincoln, Y.S. (1994). Competing paradigms in qualitative research. In Denzin, N.K., \& Lincoln, Y.S. (Eds.), Handbook of qualitative research. Thousand Oaks, CA: Sage.

Hsieh, H-F., Shannon, S. (2005). Three Approaches to Qualitative Content Analysis. Qualitative Health Research, 15 (9), 1277-1288.

Jamieson, W. (2008). Factors Related to Successful Mobilization of Communities for Crime Prevention. Institute for the Prevention of Crime, 2, 11-33.

Kelling, G.L. (1985). Order maintenance, the quality of urban life, and police: A line of argument. In Geller, W.A. (Ed.), Police leadership in America crisis and opportunity. New York: Praeger.

Kelly, K. \& Caputo, T. (2011). Community: A contemporary analysis of policies, programs, and practices. Canada: University of Toronto Press.

Klockars, C.B. (1989). The rhetoric of community policing. In Greene, J.R and Mastrofski, S.D. (Eds.), Community policing: Rhetoric or reality? (p.239-258) New York: Praeger.

Loree, D. (1993).Innovation and Change in a Regional Police Force. In Chacko, J., \& Nancoo, S.E. (Eds.), Community policing in Canada (p.139-183). Toronto: Canadian Scholars' Press Inc.

Manning, P.K. (1977). Police Work. Cambridge, MA: MIT Press. 
Manning, P.K. (1984). Community policing. American Journal of Police, 3(2), 205-230.

Manning, P.K. (1988). Community policing as a drama of control. In Greene, J.R and Mastrofski, S.D. (Eds.), Community policing: Rhetoric or reality?. New York: Praeger.

McConville, M. \& Shepherd, D. (1992). Watching policing, watching communities. London: Routledge.

Murphy, C. (1988). "The Development, Impact and Implications of Community Policing in Canada." In Greene, J.R and Mastrofski, S.D. (Eds.), Community policing: Rhetoric or reality?. New York: Praeger.

Normandeau, A., \& Bayley, L. (1990). Vision of the future of policing in Canada. Ottawa: Ministry of the Solicitor General of Canada.

Newby, H. (1980). Community. Buckingham:The Open University Press.

Ontario Ministry of the Solicitor General. (2010). Ontario regulation 266/10 made under the Police Services Act. Service Ontario. Retrieved January 2013. From http://www.elaws.gov.on.ca/html/source/regs/english/2010/elaws_src_regs_r1026 6_e.htm.

Ottawa Neighbourhood Watch. (2008). Handbook: How to get a watch going and keep it going. Ottawa Police Service. Retrieved January 2013. From http://cpc.ottawapolice.ca/file.asp?content_id=35

Ottawa Police Service. (2011). Community Police Centre Operations Guide. Ottawa Police Service. Retrieved January 2013. From http://cpc.ottawapolice.ca/view_posting.cfm?pg=1\&name=313.

Ottawa Police Service. (2013). About the OPS. Ottawa Police Service. Retrieved January 2013. From http://www.ottawapolice.ca/en/AboutOPS/abouttheops.aspx.

Ottawa Police Service. (2013). The Online Community Police Centre. Ottawa Police Service. Retrieved January 2013. From http://cpc.ottawapolice.ca/main.cfm.

Palmiotto, M.J. (2011. Community policing: A police-citizen partnership. New York: Routledge.

Potter, W.J., \& Levine-Donnerstein, D. (1999). Rethinking validity and reliability in content analysis. Journal of Applied Communication Research, 27, 258-284.

Remenyi, D. (2012). Case study research. United Kingdom: Ridgeway Press. 
Roberg, R. (1994). Can Today's Police Organizations Effectively Implement Community Policing? In Rosembaum, D. (Ed.), The challenge of community policing: Testing the promises (p.249-257). Thousand Oaks, CA: Sage Publications.

Rose, N. (1999). Powers of freedom: Reframing political thought. Cambridge: Cambridge University Press.

Rose, N., \& Miller, P. (1992). Political power beyond the state: Problematics of government. British Journal of Sociology, 43 (2), 173-205.

Rose, N., O’Malley, P. \& Valverde, M. (2006). Governmentality. Annual Review of Law and Social Sciences, 2, 83-104.

Sadd, S. \& Grinc, R. (1994).Innovative Neighbourhood Oriented Policing: An evaluation of community policing programs in eight cities. In Rosembaum, D. (Ed.), The challenge of community policing: Testing the promises (p.27-52). Thousand Oaks, CA: Sage Publications.

Skogan, W. (1994). The Impact of Community Policing on Neighbourhood Residents: A cross-site analysis. In Rosembaum, D. (Ed.), The challenge of community policing: Testing the promises (p.167-180). Thousand Oaks, CA: Sage Publications.

Skogan, W. (1996). The community's role in community policing. National Institute of Justice Journal, August, 31-34.

Skogan, W., \& Harnett, S. (2006). Police and Community Chicago Style. New York: Oxford University Press.

Skolnick, J. \& Bayley, D. (1986). The new blue line: Police innovations in six American cities. New York: Free Press.

Skolnick, J. \& Bayley, D. (1988). Community policing: Issues and practices throughout the world. Washington, DC: National Institute of Justice.

Titscher, S., Meyer, M., Wodak, R., Vetter, E. (2000). Methods of text and discourse analysis. London: Sage Publications.

Trojanowicz, R., \& Bucqueroux, B. (1990). Community policing: A contemporary perspective. Cincinnati, $\mathrm{OH}$ :Anderson.

Trojanowicz, R., Kappeler, V.E., \& Gaines, L.K. (2002). Community policing: A contemporary perspective. Cincinnati: Anderson Publishing Co. 
Walker, S. \& Walker, C. (1993). The Victoria Community Police Stations: An exercise in innovation. In Chacko, J., \& Nancoo, S.E. (Eds.), Community policing in Canada (p. 47-91). Toronto: Canadian Scholars' Press Inc.

Willis, J.J. (2001). Police: Community policing. In Dressler, J. (Ed.), The Encyclopedia of Crime and Justice. New York: Macmillan Press.

Wilkinson, D. \& Rosenbaum, D. (1994).The Effects of Organizational Structure on Community Policing: A comparison of two cities. In Rosembaum, D. (Ed.), The challenge of community policing: Testing the promises (p.110-126). Thousand Oaks, CA: Sage Publications.

Wycoff, M.A. (1988). The benefits of community policing: Evidence and conjecture. In Greene, J.R and Mastrofski, S.D. (Eds.), Community policing: Rhetoric or reality?. New York: Praeger.

Yin, R.K. (1989).Case study research. California: Sage Publications. 